\title{
Fault Feature Analysis of a Cracked Gear Coupled Rotor System
}

\author{
Hui Ma, Rongze Song, Xu Pang, and Bangchun Wen \\ School of Mechanical Engineering and Automation, Northeastern University, Shenyang, Liaoning 110819, China \\ Correspondence should be addressed to Hui Ma; mahui_2007@163.com
}

Received 19 March 2014; Accepted 22 May 2014; Published 24 June 2014

Academic Editor: Minping Jia

Copyright (C) 2014 Hui Ma et al. This is an open access article distributed under the Creative Commons Attribution License, which permits unrestricted use, distribution, and reproduction in any medium, provided the original work is properly cited.

\begin{abstract}
Considering the misalignment of gear root circle and base circle and accurate transition curve, an improved mesh stiffness model for healthy gear is proposed, and it is validated by comparison with the finite element method. On the basis of the improved method, a mesh stiffness model for a cracked gear pair is built. Then a finite element model of a cracked gear coupled rotor system in a one-stage reduction gear box is established. The effects of crack depth, width, initial position, and crack propagation direction on gear mesh stiffness, fault features in time domain and frequency domain, and statistical indicators are investigated. Moreover, fault features are also validated by experiment. The results show that the improved mesh stiffness model is more accurate than the traditional mesh stiffness model. When the tooth root crack appears, distinct impulses are found in time domain vibration responses, and sidebands appear in frequency domain. Amplitudes of all the statistical indicators ascend gradually with the growth of crack depth and width, decrease with the increasing crack initial position angle, and firstly increase and then decrease with the growth of propagation direction angle.
\end{abstract}

\section{Introduction}

A crack may initiate under the alternative load, which will reduce the structural strength and may lead to tooth fracture with crack propagation. Tooth fracture is the most serious fault in gear box and it may cause complete failure of the gear. If the tooth crack can be detected early and crack propagation can be monitored, a disastrous breakdown can be avoided by replacing damaged gear. The status of the tooth crack can be evaluated by the vibration response of the gear pair or gear coupled rotor system for condition monitoring purposes.

Vibration response of the gear pair is closely related to the time-varying mesh stiffness (TVMS) of the gear pair. Many researchers have developed many analytical methods to study the TVMS of healthy gears [1-9]. Considering Hertzian energy, bending energy, and axial compressive energy, Yang and Lin [1] calculated the TVMS of a gear pair by the potential energy principle. And this model was further refined by Tian [2] and $\mathrm{Wu}$ [3] by taking the shear energy into consideration. Assuming the gear body as a cantilever beam in the half plane, Zhou et al. [4] took the effect of the fillet foundation deflection into account and improved the method to calculate the TVMS. Based on the corrected tooth foundation deformation proposed by Sainsot et al. [5], Chaari et al. [6] developed a model to calculate the TVMS. Considering that root circle and base circle are misaligned exactly, Wan et al. [7] developed a modified method to obtain the TVMS accurately by judging the number of gear teeth. Including the effect of the gear tooth errors, Chen and Shao [8] proposed a general analytical mesh stiffness model. Considering the friction and the possibility of contacts on both flanks, Fernandez Del Rincon et al. [9] presented a procedure for determining the TVMS. In addition to the analytical methods, many researchers also applied finite element (FE) model to calculate TVMS [10-14].

Investigations on cracked gears have also been carried out by many researchers. A lot of researches focused on the crack propagation and the effect of the rim thickness on the crack propagation paths [15-18]. In order to study the effect of crack propagation on the TVMS, different models of cracked gears were also developed based on analytical method and FE method. Based on the potential energy method proposed by Yang and Lin [1], Tian [2] discussed the effects of a chipped tooth, a cracked tooth, and a broken tooth on TVMS by considering the shear energy and compared the vibration acceleration responses of the gear system under different fault types. On the basis of [2], Wu et al. [19] studied the effects of tooth crack growth on the vibration response of a one-stage 
gearbox with spur gears by computer simulation and developed an analytical model for calculating the TVMS under a cracked tooth with different crack levels. Chaari et al. [6] presented an original analytical model of tooth crack, quantified the gear mesh stiffness reduction due to spur gear tooth crack, and verified the results obtained analytically by comparing with the results of FE model. Considering the tooth root crack propagations along both tooth width and crack depth, Chen and Shao [20] proposed an analytical model to investigate the effect of gear tooth crack on the TVMS. By this analytical formulation, the mesh stiffness of a spur gear pair with different crack lengths and depths can be obtained. Based on an improved potential energy method, Zhou et al. [4] developed a modified mathematical model for simulating gear crack from root with linear growth path in a pinion by considering the deformation of gear body. By assuming a parabolic curve instead of a straight line to deal with the tooth thickness reduction, Mohammed et al. [21] presented a new method to calculate the TVMS of the gear pair for a propagating crack in the tooth root and investigated the influence of gear mesh stiffness on the vibration-based fault detection indicators, the RMS, Kurtosis, and the crest factor.

As the above literatures show, extensive efforts have been devoted to study the TVMS of meshing gear pairs with or without tooth crack. However, previous studies mostly focused on gears themselves [20-22], and in fact gear transmission systems are only one part of the whole rotor system. To study the dynamic characteristics of the whole rotor system better, the flexibility of shafts needs to be considered [23-31]. Kahraman et al. [23] developed a FE model of a geared rotor system on flexible bearings, including rotary inertia, axial loading, stiffness, and damping of the gear mesh. Kubur et al. [25] established a dynamic FE model of a helical gear transmission multi-parallel-shaft rotor system and analyzed its dynamic characteristics. Taking the flexural, rotary, and torsional degrees of freedom into account, Lee et al. [26, 27] established a FE model of a turbo-chiller rotor-bearing system with a bull-pinion speed increasing gear and analyzed the coupled natural frequencies and unbalance responses of this system. By using an extended FE model of a test gear-shaft-bearing system, Velex and Ajmi [30] compared the dynamic results from the formulations based on transmission error with the reference solutions. Ma et al. [31] established a FE model of a geared rotor system and investigated the effects of tip relief on vibration responses of this system. Omar et al. [32] presented a nine degree-of-freedom (DOF) model of a gear transmission system in which the gearbox structure is coupled with the gear shafts. Jia et al. [33] presented a dynamic model of three shafts and two pairs of gears in mesh, with 26 DOF, including the effects of TVMS, pitch and profile errors, friction, and a localized tooth crack on one of the gears.

In the abovementioned researches, the gear tooth is generally modeled as a nonuniform cantilever beam on base circle when the TVMS of spur gear is solved based on the energy method. However, root circle and base circle are misaligned exactly, so the solution error of TVMS will appear. Aiming at this situation, an improved mesh stiffness model is proposed, in which the gear tooth is simplified as a cantilever beam on the root circle. In addition, the accurate transition curve is also considered in the improved method. This study focuses on the computation of the TVMS of a cracked gear pair based on the improved mesh stiffness model. In addition, the dynamic model of cracked gear coupled rotor system is also established in which the meshing model of the gear pair with tooth crack is acquired by a lumped mass model considering TVMS and constant load torque [31]. Finally, vibration responses are obtained by Newmark- $\beta$ method and the time domain, frequency domain, and statistical indicators features are analyzed under different crack parameters.

The structure of the paper is as follows. After this introduction, mesh stiffness calculation of a spur gear pair with crack is presented in Section 2. An improved mesh stiffness model for a healthy gear pair is established and verified in Sections 2.1 and 2.2, respectively; an improved mesh stiffness model for a cracked gear pair is built in Section 2.3; on the basis of Section 2.3, TVMS for crack propagation along the tooth width is introduced in Section 2.4. In Section 3, a FE model of a cracked gear coupled rotor system is developed. Vibration responses of the cracked gear coupled rotor system are analyzed in Section 4. Effects of crack depth, width, initial position, and propagation direction on the system vibration responses are discussed in Sections 4.1, 4.2, 4.3, and 4.4, respectively. Measured vibration responses of the cracked gear coupled rotor system are performed in Section 5. Finally, conclusions are drawn in Section 6.

\section{Mesh Stiffness Calculation of a Spur Gear Pair with Crack}

2.1. An Improved Mesh Stiffness Model for a Healthy Gear Pair. In many published literatures, the gear tooth is generally modeled as a nonuniform cantilever beam on base circle. However, root circle and base circle are misaligned exactly, especially when the number of teeth is larger or smaller than 41. In this section, an improved mesh stiffness model is presented, in which the misalignment effect between the root circle and base circle is considered and the gear tooth is simplified as a cantilever beam on the root circle. In addition, the accurate transition curve is also considered in the improved method.

Before tooth profile curve equations are presented, some basic variable symbols have to be introduced: $m$ is the module, $N$ is the number of teeth, $\alpha$ is the pressure angle of the gear pitch circle, $r, r_{a}$, and $r_{b}$ are the radiuses of the pitch circle, addendum circle, and base circle of the gear, $h_{a}^{*}$ is the addendum coefficient, and $c^{*}$ is the tip clearance coefficient. Tooth profile curve can be divided into four parts, addendum curve $A B$, involute curve $B C$, transition curve $C D$, and dedendum curve $D E$ (see Figure 1). Equations of involute curve are expressed as follows:

$$
\begin{gathered}
x=r_{i} \sin \varphi, \\
y=r_{i} \cos \varphi, \\
\varphi=\frac{\pi}{2 N}-\left(\operatorname{inv} \alpha_{i}-\operatorname{inv} \alpha\right),
\end{gathered}
$$




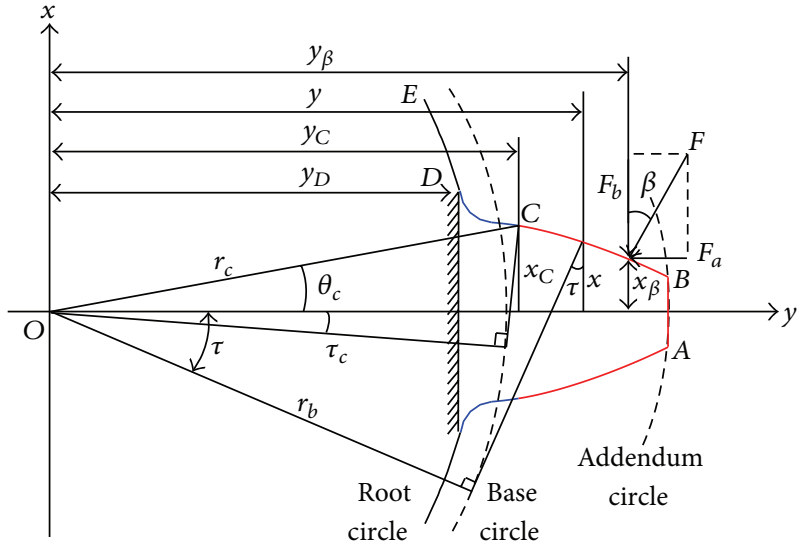

FIGURE 1: Geometric model of the gear profile.

where $r_{i}=r_{b} / \cos \alpha_{i} ; \alpha_{i}\left(\alpha_{c} \leq \alpha_{i} \leq \alpha_{a}\right)$ is the pressure angle of the arbitrary point at the involute curve, in which $\alpha_{c}=$ $\arccos \left(r_{b} / r_{c}\right)$ and $\alpha_{a}=\arccos \left(r_{b} / r_{a}\right)$ are the pressure angle of the involute starting point and the addendum circle, respectively; $r_{c}=\sqrt{\left(r_{b} \tan \alpha-h_{a}^{*} m / \sin \alpha\right)^{2}+r_{b}^{2}}$ is the radius of the involute starting point circle; inv $\alpha_{i}$ is the involute function, $\operatorname{inv} \alpha_{i}=\tan \alpha_{i}-\alpha_{i}$, inv $\alpha=\tan \alpha-\alpha$.

Transition curve is formed in the process of machining by rack, which is not engaged in meshing but is of great importance. Its equations are defined as [34]

$$
\begin{array}{r}
x=r \times \sin (\Phi)-\left(\frac{a_{1}}{\sin \gamma+r_{\rho}}\right) \times \cos (\gamma-\Phi) \\
y=r \times \cos (\Phi)-\left(\frac{a_{1}}{\sin \gamma+r_{\rho}}\right) \times \sin (\gamma-\Phi) \\
\alpha \leq \gamma \leq \frac{\pi}{2},
\end{array}
$$

where $\Phi=\left(a_{1} / \tan \gamma+b_{1}\right) / r, r_{\rho}=c^{*} m /(1-\sin \alpha), a_{1}=$ $\left(h_{a}^{*}+c^{*}\right) \times m-r_{\rho}$, and $b_{1}=\pi m / 4+h_{a}^{*} m \tan \alpha+r_{\rho} \cos \alpha$.

Based on elastic mechanics, the relationships between Hertzian contact stiffness $k_{h}$, bending stiffness $k_{b}$, shear stiffness $k_{s}$, axial compressive stiffness $k_{a}$, fillet foundation stiffness $k_{f}$ and Hertzian energy $U_{h}$, bending energy $U_{b}$, shear energy $U_{s}$, axial compressive energy $U_{a}$, and fillet foundation energy $U_{f}$ are obtained, which are written as $[1,2,20]$

$$
\begin{gathered}
U_{h}=\frac{F^{2}}{2 k_{h}}, \quad U_{b}=\frac{F^{2}}{2 k_{b}}, \quad U_{s}=\frac{F^{2}}{2 k_{s}}, \\
U_{a}=\frac{F^{2}}{2 k_{a}}, \quad U_{f}=\frac{F^{2}}{2 k_{f}},
\end{gathered}
$$

where $F$ is the total acting force on the contact teeth.

The summation of Hertzian, bending, shear, and axial compressive and fillet foundation energies constitutes the total potential energy $U$ stored in a single pair of meshing teeth, which can be expressed as

$$
\begin{aligned}
U= & \frac{F^{2}}{2 k} \\
= & U_{h}+U_{b 1}+U_{s 1}+U_{a 1}+U_{f 1}+U_{b 2}+U_{s 2}+U_{a 2}+U_{f 2} \\
= & \frac{F^{2}}{2}\left(\frac{1}{k_{h}}+\frac{1}{k_{b 1}}+\frac{1}{k_{s 1}}+\frac{1}{k_{a 1}}+\frac{1}{k_{f 1}}+\frac{1}{k_{b 2}}\right. \\
& \left.\quad+\frac{1}{k_{s 2}}+\frac{1}{k_{a 2}}+\frac{1}{k_{f 2}}\right)
\end{aligned}
$$

where $k$ represents the total effective mesh stiffness of the pair of meshing teeth and subscripts 1 and 2 denote pinion and gear, respectively.

According to (4), single-tooth-pair mesh stiffness can be given as

$$
\begin{array}{r}
k=1 \times\left(\frac{1}{k_{h}}+\frac{1}{k_{b 1}}+\frac{1}{k_{s 1}}+\frac{1}{k_{a 1}}+\frac{1}{k_{f 1}}\right. \\
\left.+\frac{1}{k_{b 2}}+\frac{1}{k_{s 2}}+\frac{1}{k_{a 2}}+\frac{1}{k_{f 2}}\right)^{-1} .
\end{array}
$$

Consequently, the total TVMS of the gear pair in the mesh cycle with contact ratio between 1 and 2 can be calculated as

$$
k_{12}=\sum_{i=1}^{j} k_{i}, \quad(j=1,2)
$$

where $k_{12}$ is the total TVMS of the gear pair in the mesh cycle and $j$ denotes thenumber of meshing tooth pair at the same time.

Hertzian contact stiffness and fillet foundation stiffness $[6,20]$ can be found in $(7)$ and $(8)$ :

$$
k_{h}=\frac{\pi E L}{4\left(1-v^{2}\right)}
$$

where $E, L$, and $v$ represent Young's modulus, tooth width, and Poisson's ratio, respectively:

$$
\frac{1}{k_{f}}=\frac{\cos ^{2} \beta}{E L}\left\{L^{*}\left(\frac{u_{f}}{S_{f}}\right)^{2}+M^{*}\left(\frac{u_{f}}{S_{f}}\right)+P^{*}\left(1+Q^{*} \tan ^{2} \beta\right)\right\},
$$

where $\beta$ is the operating pressure angle (see Figure 1) and parameters $u_{f}, S_{f}, L^{*}, M^{*}, P^{*}$, and $Q^{*}$ can be found in [5]. 


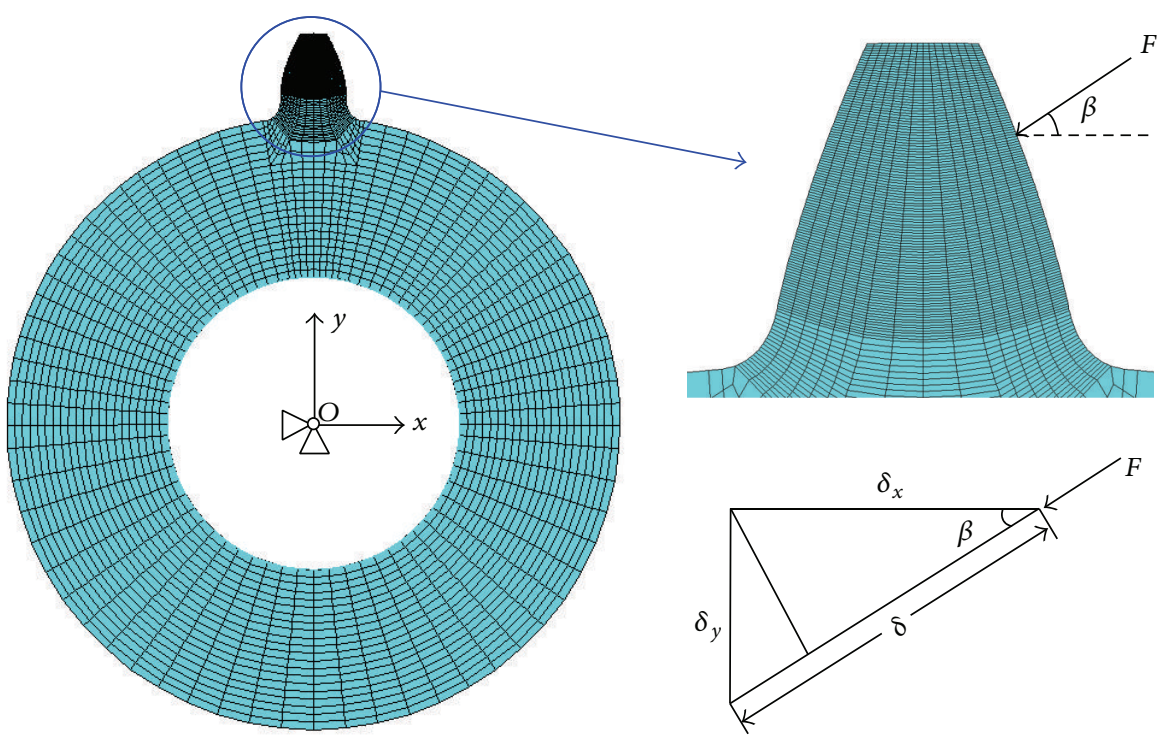

FIGURE 2: FE model of a healthy gear.

Based on the beam theory, axial compressive, bending, and shear energy of gear tooth comprised of involute and transitional part can be calculated by

$$
\begin{gathered}
U_{a}=\frac{F^{2}}{2 k_{a}}=\int_{y_{D}}^{y_{C}} \frac{F_{a}^{2}}{2 E A_{y 1}} \mathrm{~d} y_{1}+\int_{y_{C}}^{y_{\beta}} \frac{F_{a}^{2}}{2 E A_{y 2}} \mathrm{~d} y_{2}, \\
U_{b}=\frac{F^{2}}{2 k_{b}}=\int_{y_{D}}^{y_{C}} \frac{M_{1}^{2}}{2 E I_{y 1}} \mathrm{~d} y_{1}+\int_{y_{C}}^{y_{\beta}} \frac{M_{2}^{2}}{2 E I_{y 2}} \mathrm{~d} y_{2}, \\
U_{s}=\frac{F^{2}}{2 k_{s}}=\int_{y_{D}}^{y_{C}} \frac{1.2 F_{b}^{2}}{2 G A_{y 1}} \mathrm{~d} y_{1}+\int_{y_{C}}^{y_{\beta}} \frac{1.2 F_{b}^{2}}{2 G A_{y 2}} \mathrm{~d} y_{2},
\end{gathered}
$$

where $F_{b}=F \cos \beta, F_{a}=F \sin \beta, x_{\beta}$ is the distance between the contact point and the central line of the tooth, $y_{\beta}$ is the distance between the contact point and original point in the horizontal direction, $G=E / 2(1+v)$ is the shear modulus, $y_{1}, y_{2}$ represent the horizontal coordinates of arbitrary point at transition curve and involute curve, $y_{C}, y_{D}$ denote the horizontal coordinates of the starting point and ending point of the transition curve, $I_{y 1}, A_{y 1}, I_{y 2}$, and $A_{y 2}$ represent the area moment of inertia and the cross-sectional area, respectively, and torques $M_{1}=F_{b}\left(y_{\beta}-y_{1}\right)-F_{a} x_{\beta}$ and $M_{2}=$ $F_{b}\left(y_{\beta}-y_{2}\right)-F_{a} x_{\beta}$ denote the bending effect of $F_{b}$ and $F_{a}$ on the part of transition and involute curves.

For convenience, angular displacement is adopted in the calculation. According to the characteristics of involute and transition curve, $x_{\beta}, y_{\beta}, x_{1}, y_{1}, x_{2}, y_{2}, I_{y 1}, I_{y 2}, A_{y 1}$, and $A_{y 2}$ can be expressed as the functions of angular $\gamma, \beta$, or $\tau$ (see the appendix), and then axial compressive, bending, and shear stiffness can be written as follows based on (9):

$$
\frac{1}{k_{a}}=\int_{\pi / 2}^{\alpha} \frac{\sin ^{2} \beta}{E A_{y 1}} \frac{\mathrm{d} y_{1}}{\mathrm{~d} \gamma} \mathrm{d} \gamma+\int_{\tau_{c}}^{\beta} \frac{\sin ^{2} \beta}{E A_{y 2}} \frac{\mathrm{d} y_{2}}{\mathrm{~d} \tau} \mathrm{d} \tau
$$

$$
\begin{aligned}
\frac{1}{k_{b}}= & \int_{\pi / 2}^{\alpha} \frac{\left[\cos \beta\left(y_{\beta}-y_{1}\right)-x_{\beta} \sin \beta\right]^{2}}{E I_{y 1}} \frac{\mathrm{d} y_{1}}{\mathrm{~d} \gamma} \mathrm{d} \gamma \\
& +\int_{\tau_{c}}^{\beta} \frac{\left(\cos \beta\left(y_{\beta}-y_{2}\right)-x_{\beta} \sin \beta\right)^{2}}{E I_{y 2}} \frac{\mathrm{d} y_{2}}{\mathrm{~d} \tau} \mathrm{d} \tau, \\
\frac{1}{k_{s}}= & \int_{\pi / 2}^{\alpha} \frac{1.2 \cos ^{2} \beta}{G A_{y 1}} \frac{\mathrm{d} y_{1}}{\mathrm{~d} \gamma} \mathrm{d} \gamma+\int_{\tau_{c}}^{\beta} \frac{1.2 \cos ^{2} \beta}{G A_{y 2}} \frac{\mathrm{d} y_{2}}{\mathrm{~d} \tau} \mathrm{d} \tau,
\end{aligned}
$$

where $\mathrm{d} y_{1} / \mathrm{d} \gamma$ and $\mathrm{d} y_{2} / \mathrm{d} \tau$ are shown in the appendix.

2.2. Verification for Improved Mesh Stiffness Model by FE Model. FE method is considered as an efficient and reliable tool for solving problems, and it is widely applied to calculate TVMS [10-14]. To reduce the computational time, analysis is performed by a 2D model with only one tooth (see Figure 2), which is widely used and accepted in $[6,13]$. The load is considered to be in the plane of the gear body and uniformly distributed along the tooth width. No load is applied in the axial direction and the stress is negligible. Without considering the contact between two gear teeth, meshing forces are applied on the tooth profile under the plane strain assumption. The inner ring nodes of the gear are coupled with the master node (the geometric centre of the gear), and the master node is restrained from all degrees of freedom. Subsequently, according to [21], the deformation $\delta$ in the direction of action line can be acquired by deformations $\delta_{x}$ and $\delta_{y}$, which are taken from FE model and given out as

$$
\delta=\delta_{x} \cos \beta+\delta_{y} \sin \beta .
$$

The single-tooth stiffness without considering the contact between two teeth is calculated as

$$
k_{t}=\frac{F}{\delta} .
$$




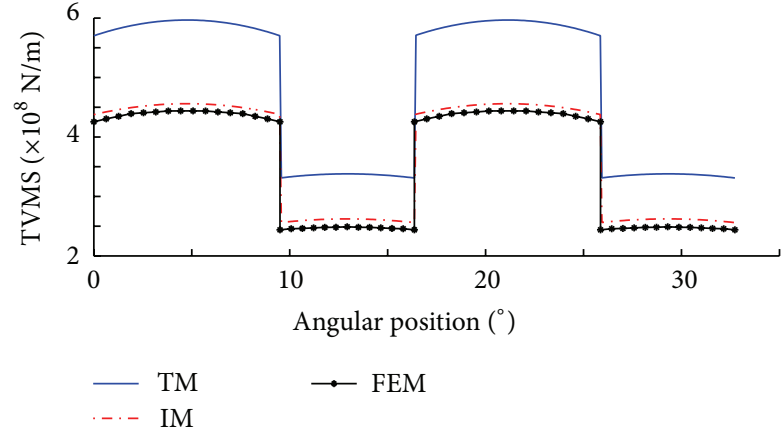

(a)

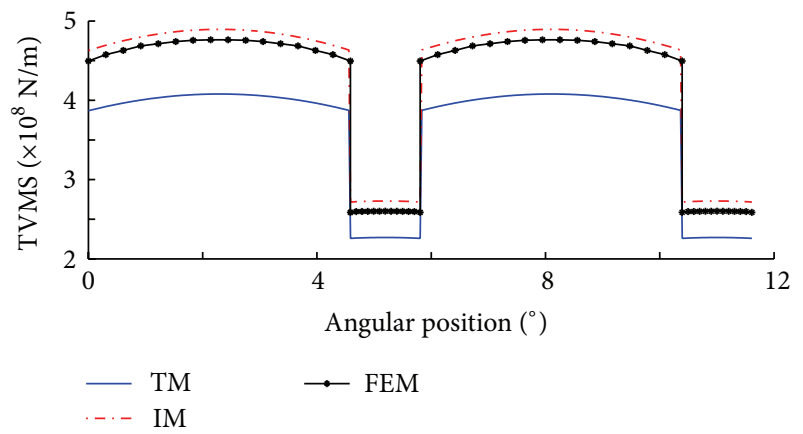

(b)

FIGURE 3: TVMS based on different methods: (a) gear pair 1, (b) gear pair 2 (TM stands for traditional method, IM improved method, and FEM finite element method).

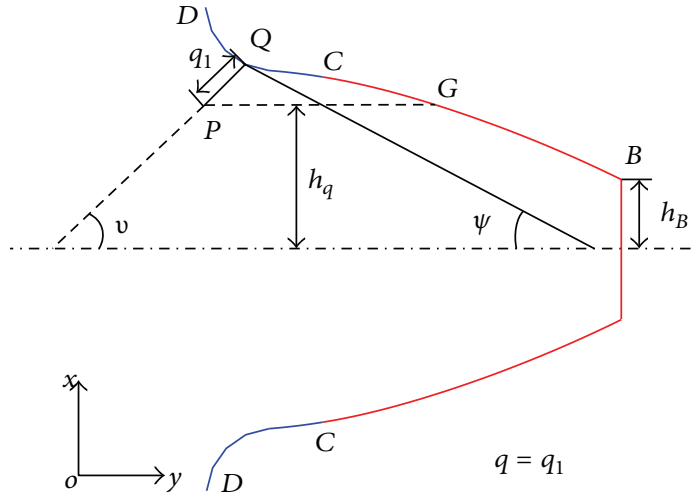

(a)

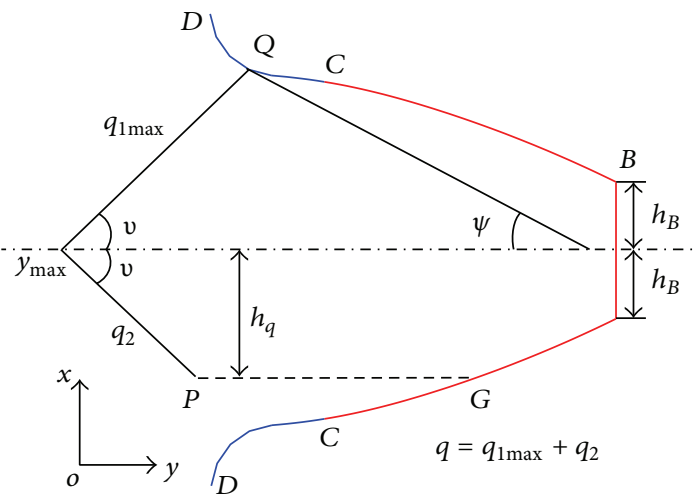

(b)

FIGURE 4: Schematic of crack propagation along the depth direction: (a) $q \leq q_{1 \max }$, (b) $q>q_{1 \max }$.

Considering the influence of Hertzian contact, $k_{h}$ is introduced, as is shown in (7), and the single-tooth-pair mesh stiffness can be given as

$$
k=\frac{1}{\left(1 / k_{h}\right)+\left(1 / k_{t 1}\right)+\left(1 / k_{t 2}\right)},
$$

where subscripts 1 and 2 denote the pinion and gear, respectively.

Two gear pairs are selected to verify the validity of the improved mesh stiffness model and their parameters are listed in Table 1. TVMS based on traditional method (TM) in which the gear tooth is modeled as a nonuniform cantilever beam on the base circle, improved method (IM) in which the gear tooth is simplified as a cantilever beam on the root circle and FE method (FEM) with precise profile curve are displayed in Figure 3. Obviously, the results from IM and FEM show good agreement, while TM shows great difference from FEM. Thus it can be seen that IM is more accurate to calculate the TVMS than TM compared with the result of FEM.

\subsection{An Improved Mesh Stiffness Model for a Cracked Gear} Pair. In order to simplify the crack model, the crack path is assumed to be a straight. The crack starts at the root of the driven gear and then propagates, as is shown in Figure 4. The
TABLE 1: Parameters of spur gear pairs.

\begin{tabular}{lcccc}
\hline \multirow{2}{*}{ Parameters } & \multicolumn{2}{c}{ Gear pair 1 } & \multicolumn{2}{c}{ Gear pair 2} \\
& Pinion & Gear & Pinion & Gear \\
\hline Number of teeth $N$ & 22 & 22 & 62 & 62 \\
Young's modulus $E(\mathrm{GPa})$ & 206 & 206 & 206 & 206 \\
Poisson's ratio $v$ & 0.3 & 0.3 & 0.3 & 0.3 \\
Module $m(\mathrm{~mm})$ & 3 & 3 & 3 & 3 \\
Addendum coefficient $h_{a}{ }^{*}$ & 1 & 1 & 1 & 1 \\
Tip clearance coefficient $c^{*}$ & 0.25 & 0.25 & 0.25 & 0.25 \\
Face width $L(\mathrm{~mm})$ & 20 & 20 & 20 & 20 \\
Pressure angle $\alpha\left(^{\circ}\right)$ & 20 & 20 & 20 & 20 \\
Hub bore radius $r_{\text {int }}(\mathrm{mm})$ & 11.7 & 11.7 & 35.7 & 35.7 \\
\hline
\end{tabular}

geometrical parameters of the crack $(q, v, \psi)$ are presented in Figure 4, in which $q$ denotes the crack depth, $v$ the crack propagation direction, and $\psi$ the crack initial position.

Assume that the crack extends along the whole tooth width with a uniform crack depth distribution and the tooth with this crack is still considered as a cantilevered beam. The curve of the tooth profile remains perfect and the foundation stiffness is not affected. In this case, based on (7), the Hertzian 
contact stiffness will still be a constant since the work surface of the tooth has no defect and the width of the effective work surface will always be a constant $L$. For the axial compressive stiffness, it will be considered the same with that under the perfect condition in that the crack part can still bear the axial compressive force as if no crack exists. Therefore, for the gear with a cracked tooth, Hertzian, fillet foundation, and axial compressive stiffness can still be calculated according to (7), (8), and (10), respectively. However, the bending and shear stiffnesses will change due to the influence of the crack. Therefore, based on (5) single-tooth-pair mesh stiffness for a cracked gear pair can be calculated as

$$
\begin{aligned}
k=1 \times( & \frac{1}{k_{h}}+\frac{1}{k_{b 1}}+\frac{1}{k_{s 1}}+\frac{1}{k_{a 1}}+\frac{1}{k_{f 1}} \\
& \left.+\frac{1}{k_{b_{-} \text {crack }}}+\frac{1}{k_{s_{\text {_crack }}}}+\frac{1}{k_{a 2}}+\frac{1}{k_{f 2}}\right)^{-1},
\end{aligned}
$$

where $k_{b_{\text {_crack }}}$ and $k_{s_{-} \text {crack }}$ denote bending and shear stiffnesses when a crack is introduced and subscripts 1 and 2 represent pinion and gear, respectively.

When the tooth crack is present and $q \leq q_{1 \max }$ (see Figure 4(a)), the effective area moment of inertia and area of the cross section at the position of $y$ can be calculated as

$$
\begin{gathered}
I= \begin{cases}\frac{1}{12}\left(h_{q}+x\right)^{3} L, & y_{P} \leq y \leq y_{G} \\
\frac{1}{12}(2 x)^{3} L=\frac{2}{3} x^{3} L, & y<y_{P} \text { or } y>y_{G},\end{cases} \\
A= \begin{cases}\left(h_{q}+x\right) L, & y_{P} \leq y \leq y_{G} \\
2 x L, & y<y_{P} \text { or } y>y_{G},\end{cases}
\end{gathered}
$$

where $h_{q}$ is the distance from the root of the crack to the central line of the tooth, which corresponds to point $G$ on the tooth profile, and $h_{q}$ can be calculated by

$$
h_{q}=x_{\mathrm{Q}}-q_{1} \sin v
$$

When the crack propagates to the central line of the tooth, $q_{1}$ reaches its maximum value $q_{1 \max }=x_{\mathrm{Q}} / \sin v$. Then the crack will change direction to $q_{2}$, which is assumed to be exactly symmetric with $q_{1}$, and in this stage $q=q_{1 \text { max }}+q_{2}$ (see Figure $4(\mathrm{~b}))$. In theory, maximum value of $q_{2}$ is $q_{1 \text { max }}$; however, the tooth is expected to suffer sudden breakage before crack runs through the whole tooth; therefore, the maximum value of $q_{2}$ is smaller than $q_{1 \text { max }}$. When the crack propagates along $q_{2}$, the effective area moment of inertia and area of the cross section at the position of $y$ can be calculated as

$$
\begin{gathered}
I= \begin{cases}\frac{2}{3} x^{3} L, & y<y_{\max } \\
\frac{1}{12}\left[x-\frac{\left(y-y_{\max }\right) h_{q}}{y_{P}-y_{\max }}\right]^{3} L, & y_{\max } \leq y<y_{P} \\
\frac{1}{12}\left(x-h_{q}\right)^{3} L, & y_{P} \leq y \leq y_{G} \\
0, & y>y_{G},\end{cases} \\
A= \begin{cases}2 x L, & y<y_{\max } \\
{\left[x-\frac{\left(y-y_{\max }\right) h_{q}}{y_{P}-y_{\max }}\right] L,} & y_{\max } \leq y<y_{P} \\
\left(x-h_{q}\right) L, & y_{P} \leq y \leq y_{G} \\
0, & y>y_{G},\end{cases}
\end{gathered}
$$

where $y_{\max }$ denotes the leftmost position of crack propagation (shown in Figure 4(b)) and $h_{q}=q_{2} \sin v$.

Based on (11) and (12), the bending and shear stiffness of the cracked gear pair can be calculated. The schematic of the calculation process is presented in Figure 5.

2.4. TVMS for Crack Propagation along the Tooth Width. The mesh stiffness model proposed in [20] divided the tooth into some independent thin slices to represent the crack propagation along the tooth width, as is shown in Figure 6. When $\mathrm{d} z$ is small, the crack depth can be assumed to be a constant through the width for each slice, and stiffness of each slice denoted as $k(z)$ can be calculated by (16). Then, the stiffness of the whole tooth can be obtained by integration of $k(z)$ along the tooth width:

$$
k=\int_{0}^{L} k(z) .
$$

Assume that the crack propagation is in the plane (see A-A in Figure 6). The crack depth along tooth width can be described as a function of $z$ in the coordinate system $y^{\prime} o^{\prime} z$, which can be written as

$$
q(z)=f(z) .
$$

The distribution of the crack depth is assumed to be a parabolic function along the tooth width to investigate the influence of crack width on TVMS [20]. When the crack width is less than the whole tooth width (see the solid curve in Figure 7),

$$
\begin{gathered}
q(z)=q_{0} \sqrt{\frac{z+L_{c}-L}{L_{c}}}, \quad z \in\left[L-L_{c}, L\right] \\
q(z)=0, \quad z \in\left[0, L-L_{c}\right]
\end{gathered}
$$

where $L_{c}$ is the crack width and $q_{0}$ is the crack depth on crack starting surface.

When the crack width extends through the whole tooth width (see the dashed curve in Figure 7),

$$
q(z)=\sqrt{\frac{q_{0}^{2}-q_{e}^{2}}{L} z+q_{e}^{2},}
$$

where $q_{e}$ is the crack depth on crack ending surface. 


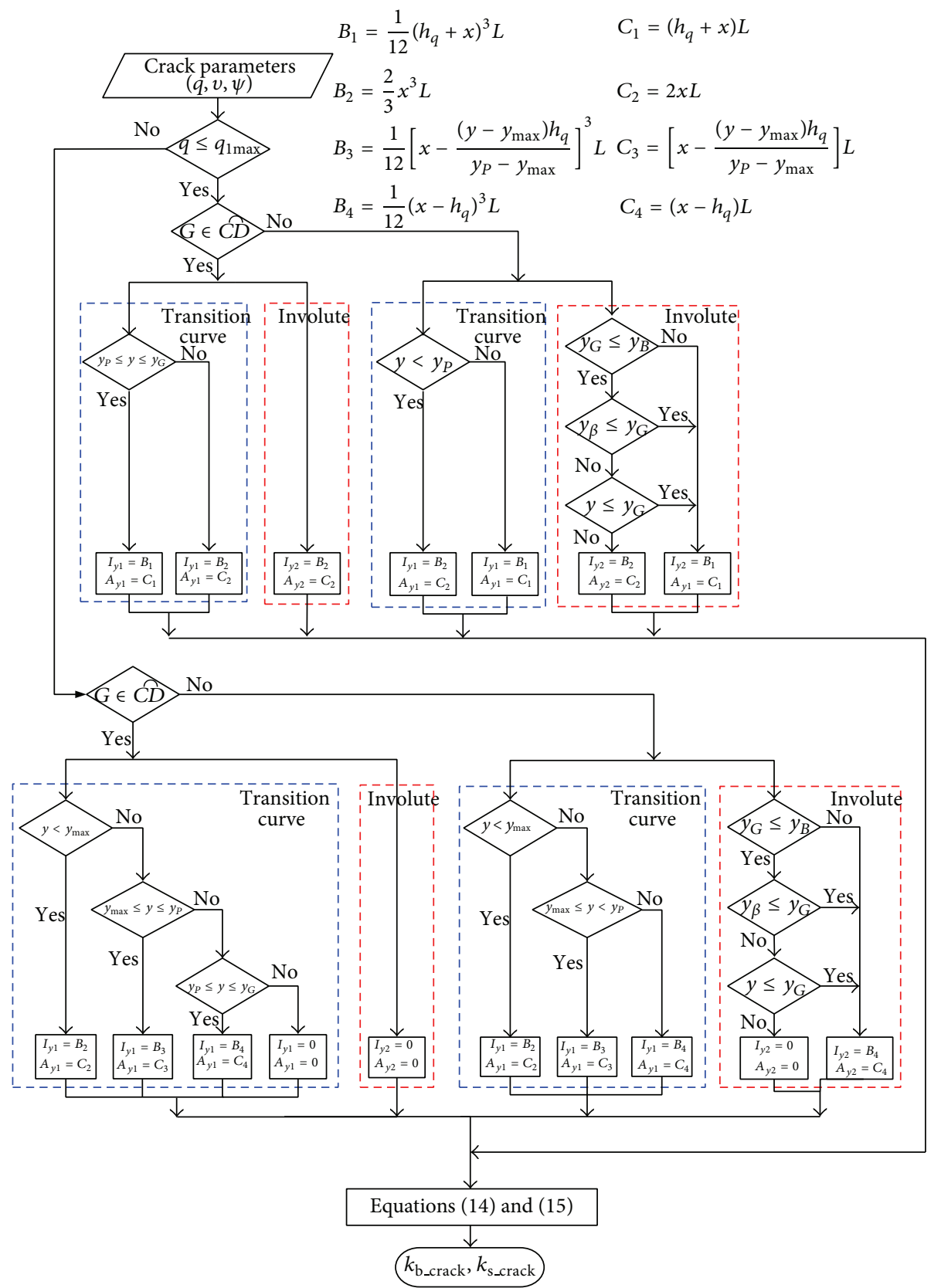

FIGURE 5: Schematic to obtain bending and shear stiffness for a cracked tooth.

\section{FE Model of a Cracked Gear Coupled Rotor System}

In order to research on fault features of a cracked gear, it is necessary to consider the dynamic characteristics of the geared rotor system which owns realistic significance. Based on [31], a geared rotor system model will be established.

Dynamic model of a spur gear pair formed by gears 1 and 2 is shown in Figure 8 where the typical spur gear meshing is represented by a pair of rigid disks connected by a springdamper set along the plane of action, which is tangent to the base circles of the gears. $O_{1}$ and $O_{2}$ are their geometrical centers, $\Omega_{1}$ and $\Omega_{2}$ are the rotating speeds, and $r_{b 1}$ and $r_{b 2}$ are the radiuses of the gear base circles, respectively. $e_{12}(t)$ denotes nonloaded static transmission error which is formed solely by the geometric deviation component. Assuming that the spur gear pair studied in the paper is perfect, nonloaded static transmission error will be zero; that is, $e_{12}(t)=0 . c_{12}(t)$ represents the mesh damping which is assumed to be zero. The angle between the plane of action and the positive $y$-axis is represented by $\psi_{12}$ defined as

$$
\psi_{12}= \begin{cases}-\alpha+\alpha_{12} & \Omega_{1}: \text { Counterclosewise } \\ \alpha+\alpha_{12}-\pi & \Omega_{1}: \text { Clockwise }\end{cases}
$$




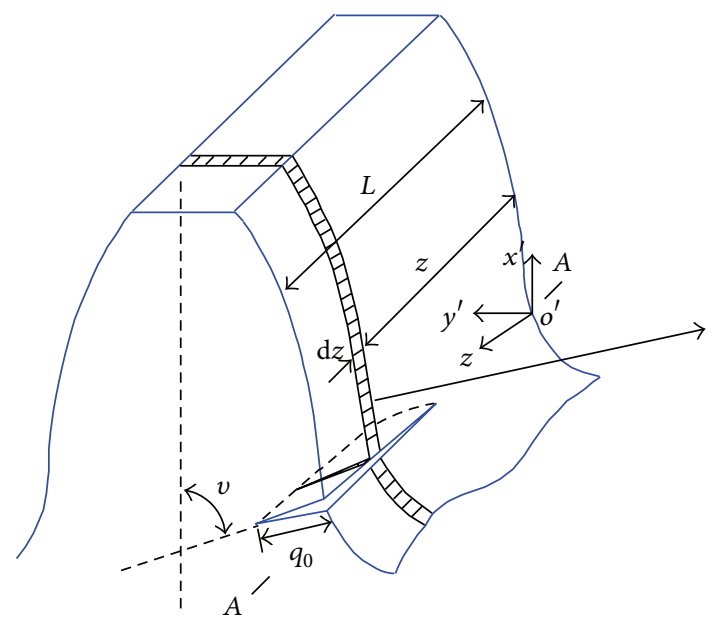

(a)

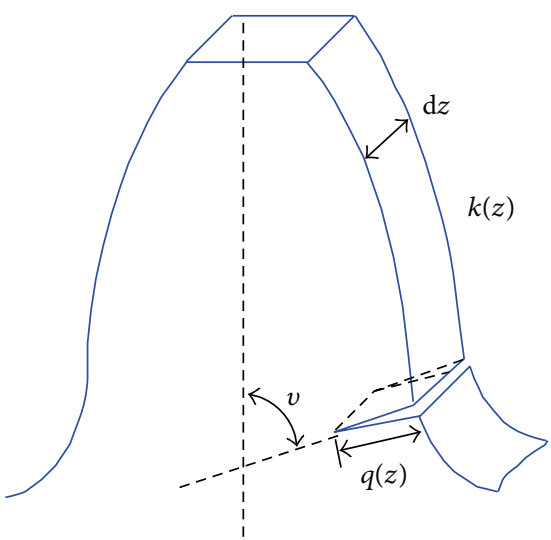

(b)

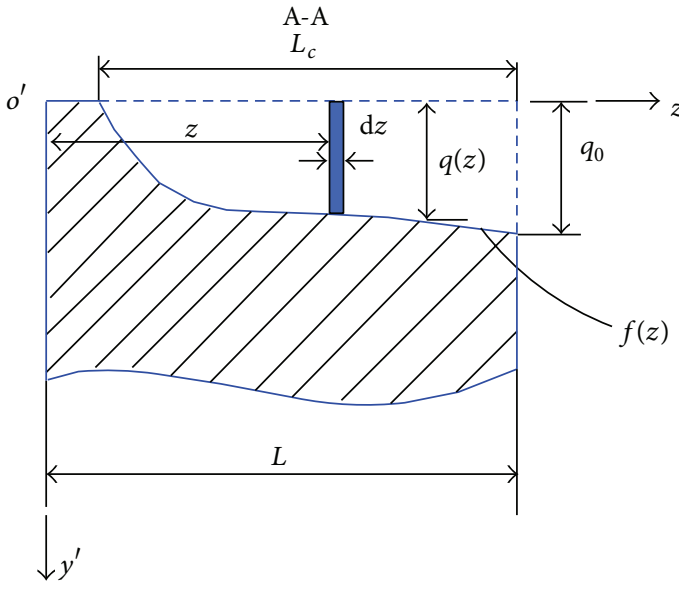

(c)

FIGURE 6: Crack model at gear tooth root.

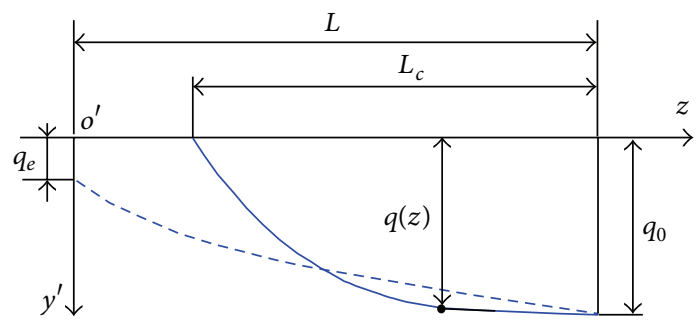

FIGURE 7: Crack depth along tooth width.

where $\alpha_{12}\left(0 \leq \alpha_{12} \leq 2 \pi\right)$ represents the angle between the line connecting the gear centers and the positive $x$-axis of the pinion and in this work, $\alpha_{12}=0$.

In order to consider the influence of the rotating direction of the pinion, the function $\sigma$ is introduced as

$$
\sigma= \begin{cases}1 & \Omega_{1}: \text { Counterclockwise } \\ -1 & \Omega_{1}: \text { Clockwise. }\end{cases}
$$

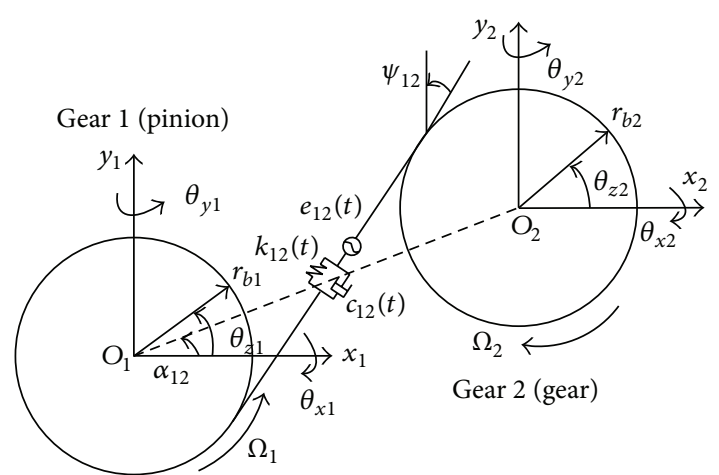

Figure 8: Dynamic model of a spur gear pair.

Each gear owns six degrees of freedom including translation in $x, y$, and $z$ directions and rotation about these three axes. With these six degrees of freedom for each gear, the gear pair has a total of 12 degrees of freedom that defines the coupling between the two shafts holding the gears. Without 
considering the tooth separation, backlash, friction forces at the mesh point, and the position change of the pressure line, the motion equations of the gear pair are written as

$$
\begin{gathered}
m_{1} \ddot{x}_{1}-k_{12} p_{12}(t) \sin \psi_{12}-c_{12}(t) \dot{p}_{12}(t) \sin \psi_{12}=0, \\
m_{1} \ddot{y}_{1}+k_{12} p_{12}(t) \cos \psi_{12}+c_{12}(t) \dot{p}_{12}(t) \cos \psi_{12}=0, \\
m_{1} \ddot{z}_{1}=0, \\
I_{x 1} \ddot{\theta}_{x 1}+I_{z 1} \Omega_{1} \dot{\theta}_{y 1}=0, \\
I_{y 1} \ddot{\theta}_{y 1}-I_{z 1} \Omega_{1} \dot{\theta}_{x 1}=0, \\
I_{z 1} \ddot{\theta}_{z 1}+\sigma \times r_{b 1} k_{12} p_{12}(t)+\sigma \times r_{b 1} c_{12}(t) \dot{p}_{12}(t)=T_{1}, \\
m_{2} \ddot{x}_{2}+k_{12} p_{12}(t) \sin \psi_{12}+c_{12}(t) \dot{p}_{12}(t) \sin \psi_{12}=0, \\
m_{2} \ddot{y}_{2}-k_{12} p_{12}(t) \cos \psi_{12}-c_{12}(t) \dot{p}_{12}(t) \cos \psi_{12}=0, \\
m_{2} \ddot{z}_{2}=0, \\
I_{x 2} \ddot{\theta}_{x 2}+I_{z 2} \Omega_{2} \dot{\theta}_{y 2}=0, \\
I_{y 2} \ddot{\theta}_{y 2}-I_{z 2} \Omega_{2} \dot{\theta}_{x 2}=0, \\
I_{z 2} \ddot{\theta}_{z 2}+\sigma \times r_{b 2} k_{12} p_{12}(t)+\sigma \times r_{b 2} c_{12}(t) \dot{p}_{12}(t)=T_{2},
\end{gathered}
$$

where $m_{1}$ and $m_{2}$ are the mass of gears 1 and 2 and $I_{x 1}, I_{y 1}$, $I_{z 1}, I_{x 2}, I_{y 2}$, and $I_{z 2}$, respectively, represent the moments of inertia about the $x^{-}, y$-, and $z$-axis of gears 1 and 2. $T_{1}$ and $T_{2}$ are constant load torques. The term $p_{12}(t)$ represents the relative displacement of the gears in the direction of the action plane and is defined as

$$
\begin{aligned}
p_{12}(t)=( & -x_{1} \sin \psi_{12}+x_{2} \sin \psi_{12}+y_{1} \cos \psi_{12}-y_{2} \cos \psi_{12} \\
& \left.+\sigma \times r_{b 1} \theta_{z 1}+\sigma \times r_{b 2} \theta_{z 2}\right)-e_{12}(t)
\end{aligned}
$$

Equation (26) can be written in matrix form as follows:

$$
\mathbf{M}_{12} \ddot{\mathbf{X}}_{12}+\left(\mathbf{C}_{12}+\mathbf{G}_{12}\right) \dot{\mathbf{X}}_{12}+\mathbf{K}_{12} \mathbf{X}_{12}=\mathbf{F}_{12},
$$

where $\mathbf{X}_{12}$ is the displacement vector of a gear pair. $\mathbf{M}_{12}, \mathbf{K}_{12}$, $\mathrm{C}_{12}$, and $\mathbf{G}_{12}$ represent the mass matrix, mesh stiffness matrix, mesh damping matrix, and gyroscopic matrix of the spur gear pair, respectively. $\mathbf{F}_{12}$ is the exciting force vector of the spur gear pair. These matrices and vectors are defined thoroughly in [31].

Motion equations of the whole geared rotor system can be written in matrix form as

$$
\mathbf{M} \ddot{\mathbf{u}}+(\mathbf{C}+\mathbf{G}) \dot{\mathbf{u}}+\mathbf{K u}=\mathbf{F}_{\mathbf{u}},
$$

where $\mathbf{M}, \mathbf{K}, \mathbf{C}$, and $\mathbf{G}$ are the mass, stiffness, damping, and gyroscopic matrix of the global system; $\mathbf{u}$ and $\mathbf{F}_{\mathbf{u}}$ denote the displacement and external force vectors of the global system. All these matrixes and vectors can be obtained in [31].

In this paper, the cracked gear coupled rotor system includes two shafts, a gear pair with a tooth crack in the driven

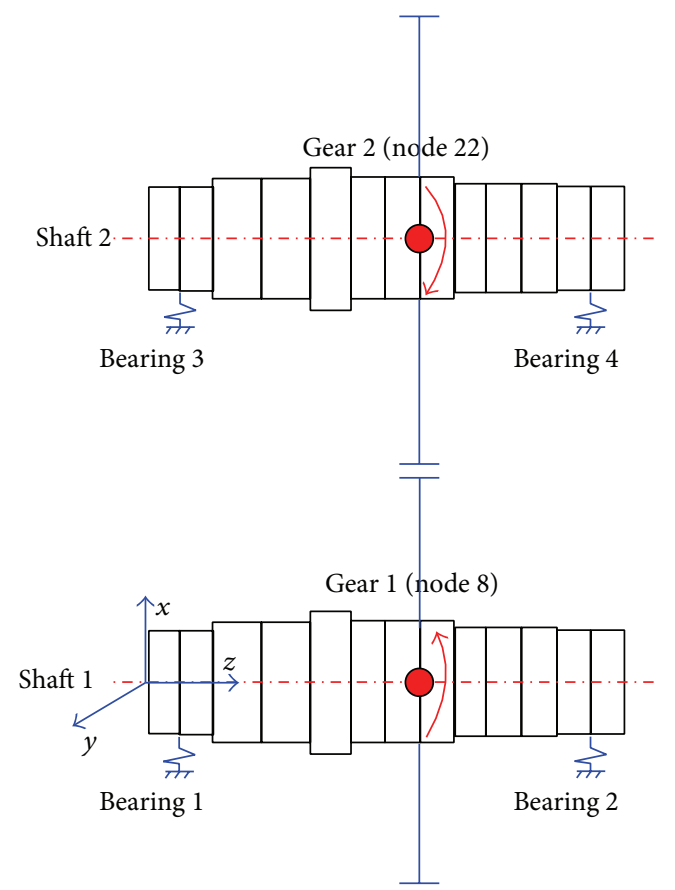

FIGURE 9: FE model of a cracked gear coupled rotor system.

gear (gear 2) and four ball bearings. The parameters of the system are listed in Table 2, and the FE model of the geared rotor system is shown in Figure 9. Material parameters of the shafts are as follows: Young's modulus $E=210 \mathrm{GPa}$, Poisson's ratio $v=0.3$, and density $\rho=7850 \mathrm{~kg} / \mathrm{m}^{3}$. Shafts 1 and 2 are both divided into 13 elements, and gears 1 and 2 are located at nodes 8 and 22, respectively (see Figure 9).

\section{Vibration Response Analysis of a Cracked Gear Coupled Rotor System}

Based on the cracked gear coupled rotor system proposed in Section 3, the system dynamic responses can be calculated by Newmark- $\beta$ numerical integration method. Firstly, a cracked gear with a constant depth $3 \mathrm{~mm}$ through the whole tooth width is chosen as an example to analyze the influence of the crack at the root of the gear on the system vibration responses. The parameters are as follows: rotating speed of gear $1 \Omega_{1}=$ $1000 \mathrm{rev} / \mathrm{min}, \psi=35^{\circ}, v=45^{\circ}$, and crack depth $q=3 \mathrm{~mm}$ ( $q_{1 \max }=3.2 \mathrm{~mm}$ under these parameters).

In this paper, vibration responses at right journal of the driving shaft in $x$ direction are selected to analyze the fault features under tooth crack condition. The acceleration responses of the healthy and cracked gears under steady state are compared and the results are shown in Figure 10. In the figure, it is shown that three distinct impulses representing the mating of the cracked tooth appear compared with the healthy condition. And the time interval between every two adjacent impulses is exactly equal to the rotating period of the driven gear $(0.0818 \mathrm{~s})$ because the influence caused by cracked tooth repeats only once in a revolution of the driven gear. In order to clearly reflect the vibration features when the tooth 
TABLE 2: Parameters of the cracked gear coupled rotor system.

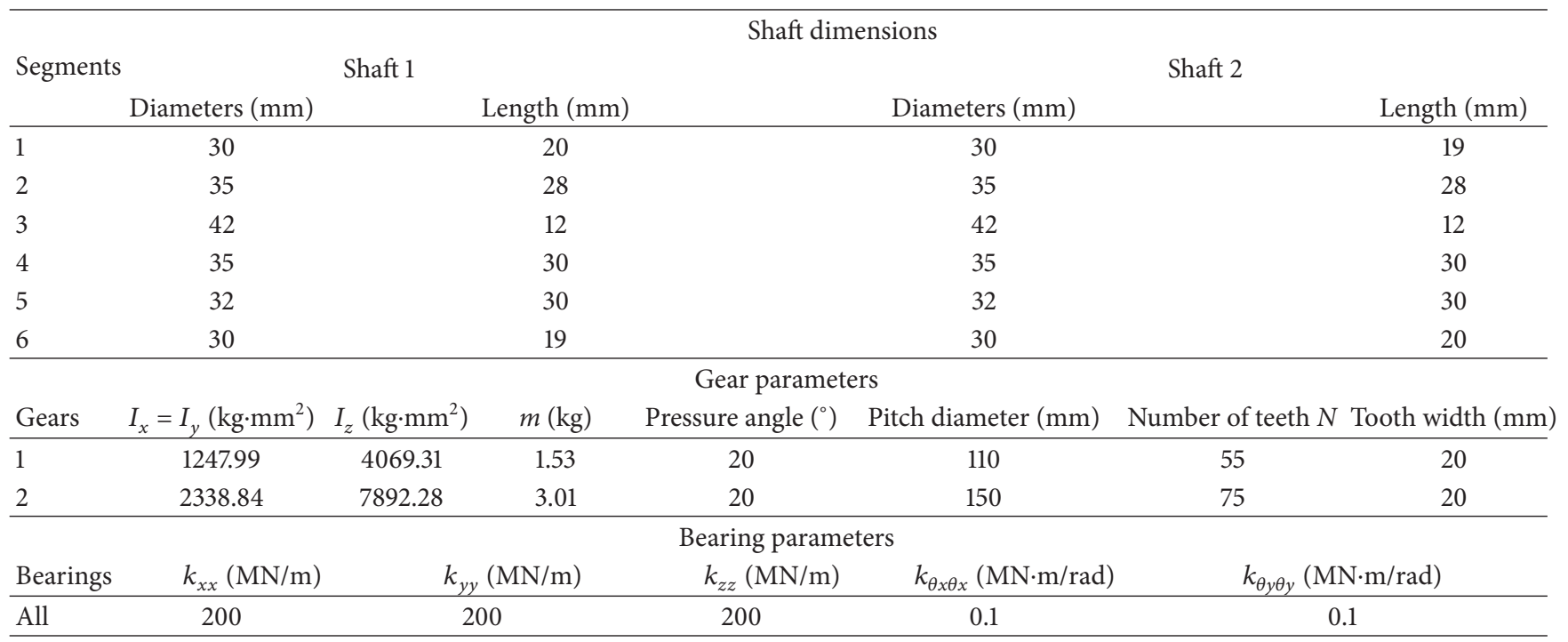

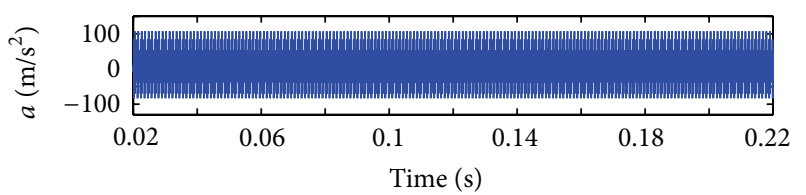

(a)

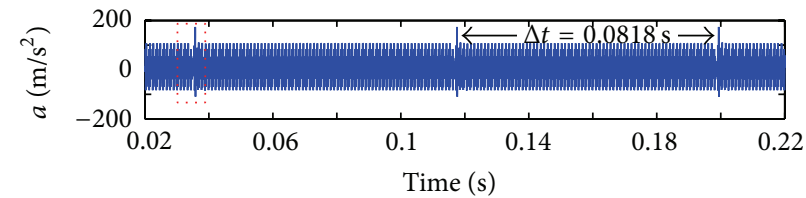

(b)

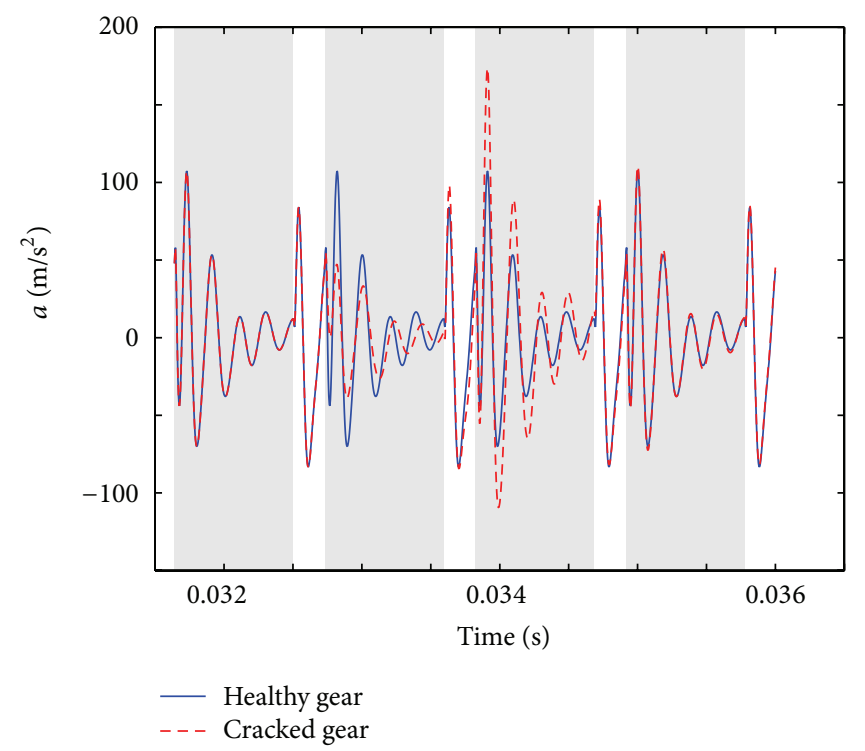

(c)

FIGURE 10: Accelerations in time domain: (a) healthy gear, (b) cracked gear, and (c) enlarged view.

with crack is in mesh, the enlarged views of vibration acceleration are displayed in Figure 10(c), in which the gray region represents the double-tooth meshing area and the white region denotes the single-tooth meshing area. From the figure, it can be seen that the vibration level increases apparently compared with that of the healthy gear.

Amplitude spectra of the acceleration are shown in Figure 11. In the figure, $f_{e}$ denotes the meshing frequency
(916.67 Hz). The figure shows that the amplitudes of $f_{e}$ and those of its harmonics $\left(2 f_{e}, 3 f_{e}\right.$, etc.) for the cracked gear hardly change compared with the healthy gear, but the sidebands appear under the tooth crack condition, which can be observed clearly in Figure 11(b). The interval $\Delta f$ between every two sideband components is exactly equal to the rotating frequency of the cracked gear; that is, $f_{2}=12 \mathrm{~Hz}$. So a conclusion can be drawn that the sideband components can be used to diagnose the crack fault of gear. 
TABLE 3: Crack case data under different crack depths.

\begin{tabular}{|c|c|c|c|c|c|c|c|c|c|}
\hline $\begin{array}{l}\text { Crack } \\
\text { case }\end{array}$ & $\begin{array}{c}\text { Crack } \\
\text { depth (\%) }\end{array}$ & $\begin{array}{l}\text { Crack size } \\
(\mathrm{mm})\end{array}$ & $\begin{array}{c}\text { Crack } \\
\text { case }\end{array}$ & $\begin{array}{c}\text { Crack } \\
\text { depth (\%) }\end{array}$ & $\begin{array}{c}\text { Crack size } \\
(\mathrm{mm})\end{array}$ & $\begin{array}{c}\text { Crack } \\
\text { case }\end{array}$ & $\begin{array}{c}\text { Crack } \\
\text { depth (\%) }\end{array}$ & $\begin{array}{c}\text { Crack size } \\
(\mathrm{mm})\end{array}$ & Condition \\
\hline $1(\mathrm{~A})^{\#}$ & $0^{\#}$ & $q=0^{\#}$ & 12 & 22 & $q=1.41$ & 23 & 44 & $q=2.82$ & \multirow{11}{*}{$\begin{array}{l}\Omega_{1}=1000 \mathrm{rev} / \mathrm{min} \\
v=45^{\circ} \\
\psi=35^{\circ} \\
L_{c}=L \\
q_{e}=q_{0}=q \\
q_{1 \max }=3.21 \mathrm{~mm}\end{array}$} \\
\hline 2 & 2 & $q=0.13$ & 13 & 24 & $q=1.54$ & 24 & 46 & $q=2.95$ & \\
\hline 3 & 4 & $q=0.26$ & 14 & 26 & $q=1.67$ & 25 & 48 & $q=3.08$ & \\
\hline 4 & 6 & $q=0.39$ & 15 & 28 & $q=1.80$ & 26 & 50 & $q=3.21$ & \\
\hline 5 & 8 & $q=0.51$ & 16 & 30 & $q=1.93$ & 27 & 52 & $q=3.34$ & \\
\hline 6 & 10 & $q=0.64$ & 17 & 32 & $q=2.05$ & 28 & 54 & $q=3.47$ & \\
\hline 7 & 12 & $q=0.77$ & 18 & 34 & $q=2.18$ & 29 & 56 & $q=3.60$ & \\
\hline 8 & 14 & $q=0.90$ & 19 & 36 & $q=2.31$ & 30 & 58 & $q=3.72$ & \\
\hline 9 & 16 & $q=1.03$ & 20 & 38 & $q=2.44$ & $31(\mathrm{D})^{\#}$ & $60^{\#}$ & $q=3.85^{\#}$ & \\
\hline 10 & 18 & $q=1.16$ & $21(\mathrm{C})^{\#}$ & $40^{\#}$ & $q=2.57^{\#}$ & & & & \\
\hline $11(\mathrm{~B})^{\#}$ & $20^{\#}$ & $q=1.28^{\#}$ & 22 & 42 & $q=2.70$ & & & & \\
\hline
\end{tabular}

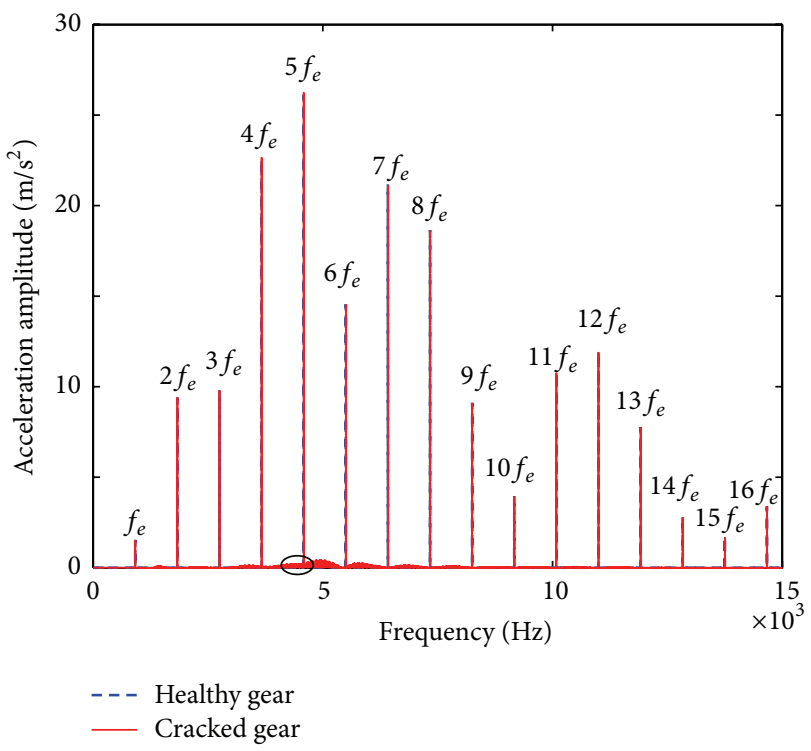

(a)

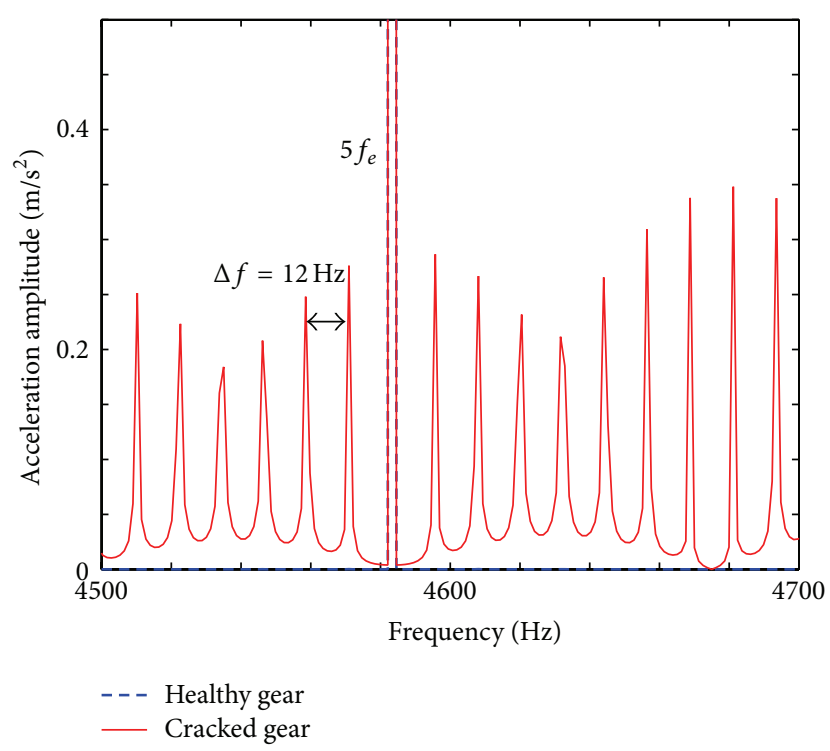

(b)

FIGURE 11: Amplitude spectra of the acceleration: (a) amplitude spectra, (b) local enlarged view $\left(f_{e}, 2 f_{e} \ldots 16 f_{e}\right.$ stand for mesh frequency and its harmonic components).

4.1. Effects of Crack Depth. In this section the angle $v$ stands for crack propagation direction and is set at a constant $45^{\circ}$, and the angle $\psi$ stands for crack initial position and is set at $35^{\circ}$. In order to analyze the influence of crack depth on the geared rotor system, 31 crack depth cases are considered, which are shown in Table 3 . The crack depth percentage is defined as the ratio of actual crack depth with theoretical through-tooth crack size. The rotating speed of gear $1 \Omega_{1}=$ $1000 \mathrm{rev} / \mathrm{min}$ (in the following study the same speed is chosen). Four cases, each of which concerns a different crack size, are selected to study the influences of different crack depths. The selected cases are case 1, which is the healthy case; case 11 which represents a smaller crack; case 21 which represents a moderate crack; finally case 31 which is a deep crack. These four cases selected for stiffness and vibration responses comparison are referred to as $\mathrm{A}, \mathrm{B}, \mathrm{C}$, and $\mathrm{D}$, respectively (see Table 3). In order to verify the validity of the improved mesh stiffness model for a cracked gear pair, a FE model is also established, in which the crack is modeled using $2 \mathrm{D}$ singularity elements (see Figure 12).

TVMS under the four crack sizes are calculated as a function of the shaft rotation angle by the improved mesh stiffness model and the FE model. And the results are shown in Figure 13. There will be eight lines when four crack cases of two models are considered. In order to clearly show the result difference between the improved method (IM) and finite element method (FEM) under different crack cases, the four cases are shown in two figures (see Figures 13(a) and 13(b)). In the figures, 1 and 2 stand for IM and FEM, respectively; A, $\mathrm{B}, \mathrm{C}$, and D stand for different crack cases. It can be seen from the figure that distinct reduction of stiffness appears when tooth crack is introduced, and the maximum stiffness 
TABLE 4: Comparisons of mean TVMS under different crack depths.

\begin{tabular}{lccccc}
\hline Case $(\mathrm{IM})$ & $k_{m}\left(\times 10^{8} \mathrm{~N} / \mathrm{m}\right)$ & Reduction percentage & Case $(\mathrm{FEM})$ & $k_{m}\left(\times 10^{8} \mathrm{~N} / \mathrm{m}\right)$ & Reduction percentage \\
\hline 1A & 3.582 & 0 & $2 \mathrm{~A}$ & 3.323 & 0 \\
1B & 3.511 & $-1.98 \%$ & $2 \mathrm{~B}$ & 3.194 & $-3.88 \%$ \\
1C & 3.327 & $-7.12 \%$ & $2 \mathrm{C}$ & 3.031 & $-8.79 \%$ \\
1D & 2.959 & $-17.39 \%$ & $2 \mathrm{D}$ & 2.869 & $-13.66 \%$ \\
\hline
\end{tabular}

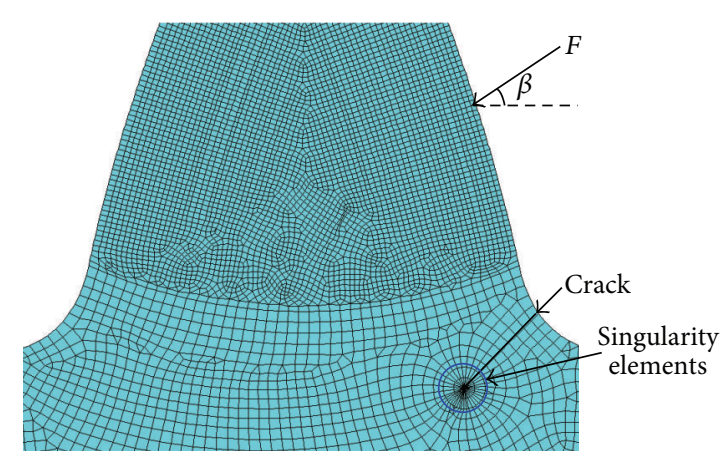

FIGURE 12: FE model of a tooth with crack.

reduction during the mesh process for a fixed crack appears where the cracked tooth is just going to engage. This is because the relative bigger flexibility of the tooth at the addendum circle compared with that at the dedendum circle. IM shows a better agreement with the FEM under small crack depth conditions, such as cases A, B, and C. The result of FEM is slightly larger than that of the IM under the large crack condition, such as case D. In order to clearly display the variation of the stiffness with crack depths, the comparisons of the mean stiffness $k_{m}$ about the four cases are shown in Table 4. In the table reduction percentages refer to the reduction percentage of the stiffness in case $\mathrm{B}$ (or $\mathrm{C}, \mathrm{D}$ ) relative to case $A$. It can be seen that the stiffness decreases with the growth of crack depth and the FEM shows the same changing trends as the IM. In the analysis of vibration responses, the TVMS acquired from IM will be used.

Vibration acceleration responses and the corresponding amplitude spectra under the four cases are shown in Figure 14. For visual convenience, only the local enlarged view is displayed. It is very hard to observe the change in acceleration waveform produced by the gear tooth root crack when it is at early stage, such as case B. However, with the growth of gear tooth crack depth, the amplitudes of the impulsive vibration signals increase. The impulses caused by tooth crack are very obvious when the crack propagates to $60 \%$ (case D). In the acceleration amplitude spectra, the magnitudes of sidebands ascend with the crack propagation along crack depth.

Statistical features which are commonly used to provide a measurement of the vibration level are widely used in mechanical fault detection [3, 20,21]. RMS and Kurtosis indicators are used to explore the effect of the crack propagation along depth [3]. The RMS value is defined as

$$
\mathrm{RMS}=\sqrt{\frac{1}{N} \sum_{n=1}^{N}(x(n)-\bar{x})^{2}}, \quad \bar{x}=\frac{1}{N} \sum_{n=1}^{N} x(n) .
$$

And Kurtosis is calculated by

$$
\text { Kurtosis }=\frac{1 / N \sum_{n=1}^{N}(x(n)-\bar{x})^{4}}{\left[1 / N \sum_{n=1}^{N}(x(n)-\bar{x})^{2}\right]^{2}} .
$$

Variation of statistical indicators of vibration acceleration with the increase of crack depth is shown in Figure 15. And indicators are acquired from two types of signals (original signal and residual signal [3]), which are shown in Figures 15(a) and 15(b), respectively. For original signals in order to reflect the vibration level compared with the healthy condition, the indicators are expressed as percentages which are defined as:

$$
\begin{gathered}
r_{\text {Kurtosis }}=\frac{\text { Kurtosis }_{\text {crack }}-\text { Kurtosis }_{\text {health }}}{\text { Kurtosis }_{\text {health }}} \times 100 \%, \\
r_{\text {RMS }}=\frac{\text { RMS }_{\text {crack }}-\text { RMS }_{\text {health }}}{\text { RMS }_{\text {health }}} \times 100 \%,
\end{gathered}
$$

where $r$ shows the relative change of cracked signal indicator, subscripts Kurtosis and RMS denote different statistical indicators, and subscripts crack and health are cracked and healthy gear.

Relative change ratios in Figure 15(b) refer to the ratios of RMS and Kurtosis with those under the maximum crack depth (60\% under this condition). It can be seen from the figures that, for original signals, RMS and Kurtosis change little when the crack depth is smaller, but when the crack depth becomes higher than $40 \%$, Kurtosis exhibits an obvious increasing trend, while RMS increases slightly. For residual signals, unlike the results obtained from original signals, RMS shows obvious increasing pattern when the crack depth exceeds 20\%. Compared with RMS, however, Kurtosis changes less obviously. So RMS acquired from residual signals is a robust indicator for early fault identification, which is similar to the results shown in [3].

4.2. Effects of Crack Width. In order to investigate the influences of crack width on the geared rotor system, 22 crack width cases are selected which are shown in Table 5 . The crack width percentage is defined as the ratio of actual crack width $L_{c}$ to the whole tooth width $(L=20 \mathrm{~mm})$. It is noted that $120 \%$ of crack width represents the case when $L_{c}=L=$ $20 \mathrm{~mm}$ and $q_{e}=q_{0}=3 \mathrm{~mm}$. Five cases corresponding to cases $1,6,11,21$, and 22 in Table 5 are referred to as A, B, C, and D and E. TVMS under the five cases are analyzed to illustrate the influences of crack width by IM (see Figure 16). Since the FE model used in the paper is a $2 \mathrm{D}$ model, it is powerless to simulate the crack propagation along the tooth width. And because the crack depth is changing along the 


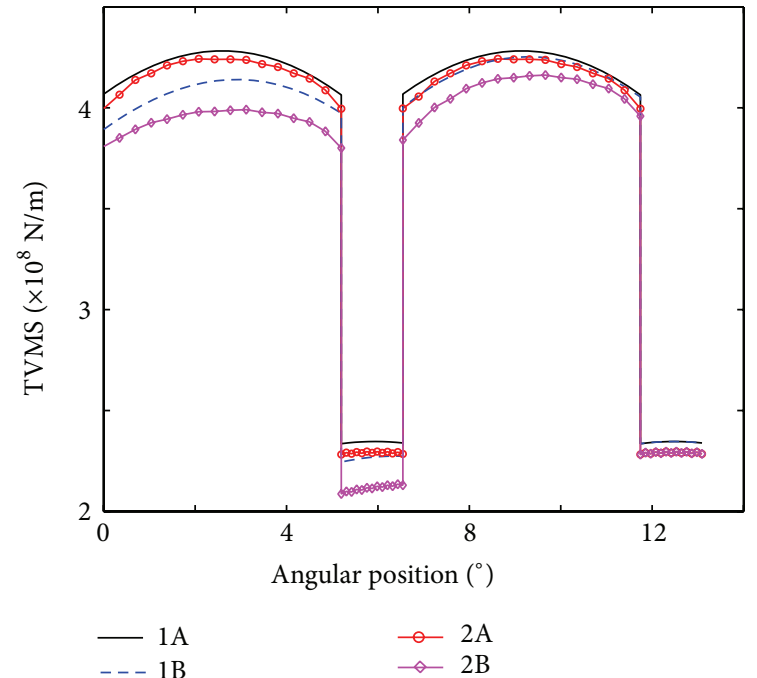

(a)

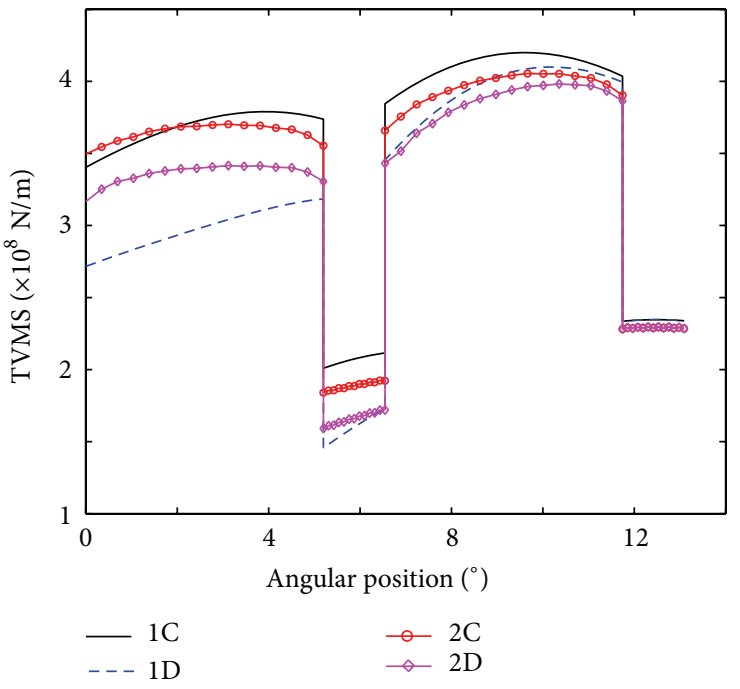

(b)

FIGURE 13: TVMS under different crack depths: (a) crack cases A and B and (b) crack cases C and D.

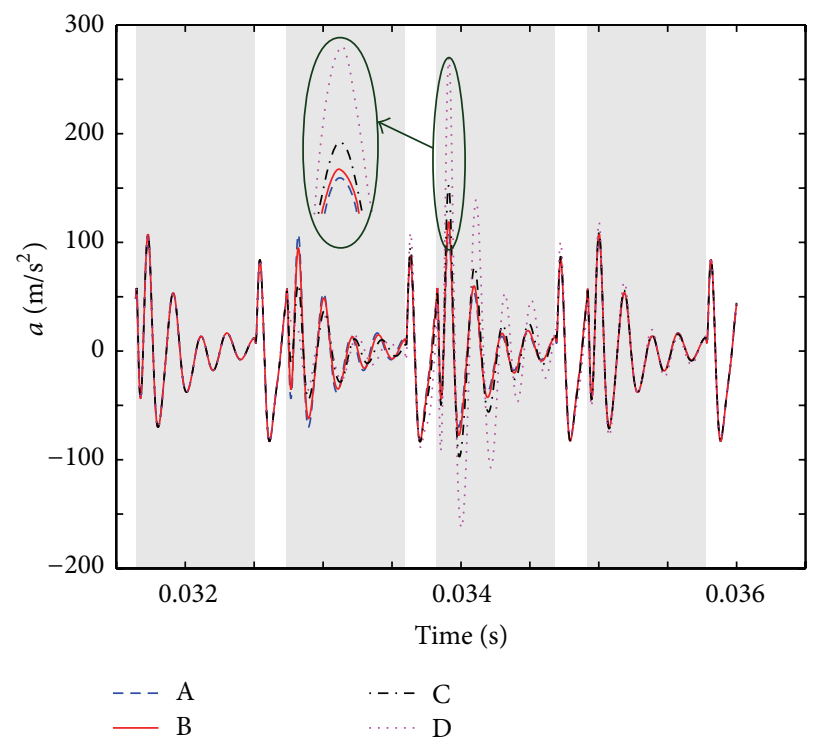

(a)

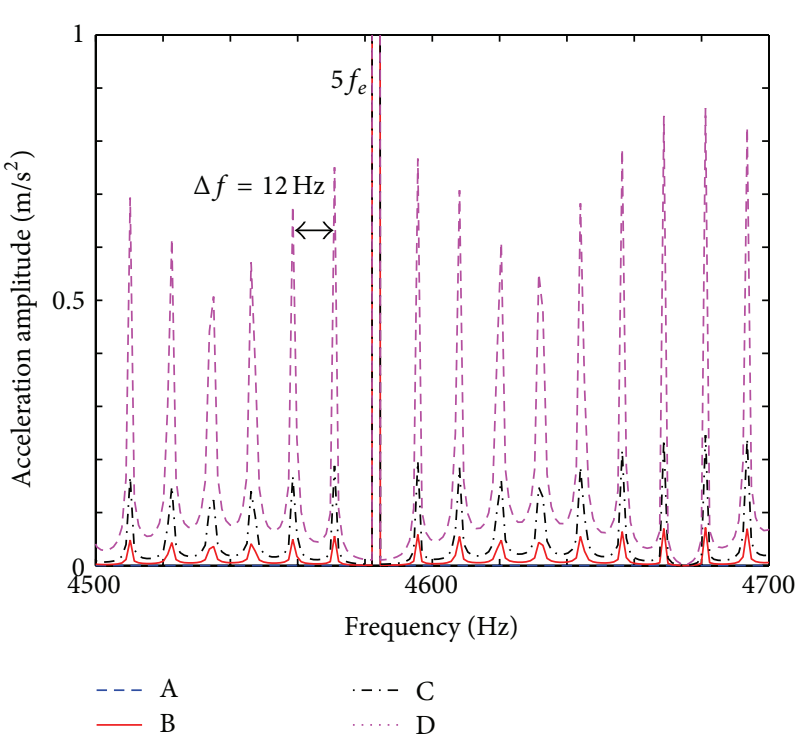

(b)

FIGURE 14: Acceleration responses under different crack depths: (a) time domain waveform and (b) amplitude spectra.

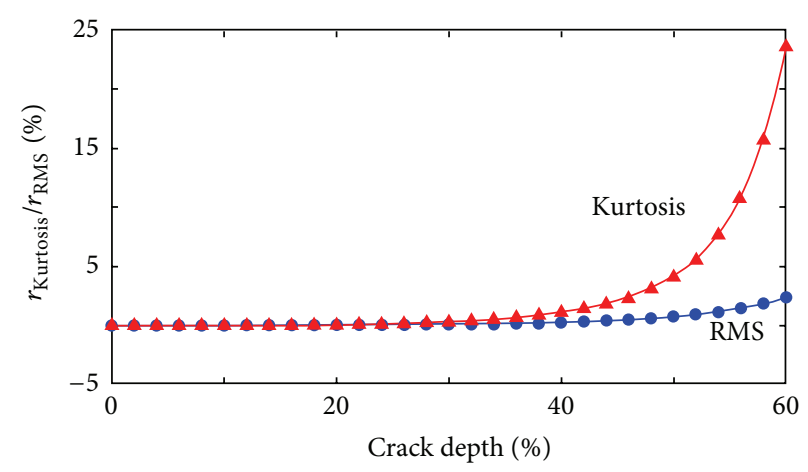

(a)

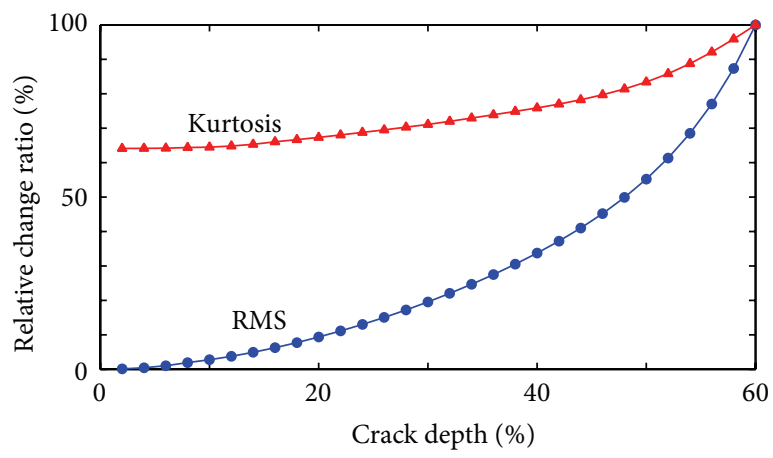

(b)

Figure 15: Acceleration statistical indicators under different crack depths: (a) original signal and (b) residual signal. 
TABLE 5: Crack propagation case data under different crack widths.

\begin{tabular}{|c|c|c|c|c|c|c|c|c|c|}
\hline $\begin{array}{l}\text { Crack } \\
\text { case }\end{array}$ & $\begin{array}{c}\text { Crack width } \\
(\%)\end{array}$ & $\begin{array}{l}\text { Crack size } \\
(\mathrm{mm})\end{array}$ & $\begin{array}{l}\text { Crack } \\
\text { case }\end{array}$ & $\begin{array}{c}\text { Crack width } \\
(\%)\end{array}$ & Crack size (mm) & $\begin{array}{l}\text { Crack } \\
\text { case }\end{array}$ & $\begin{array}{c}\text { Crack width } \\
(\%)\end{array}$ & Crack size (mm) & Condition \\
\hline $1(\mathrm{~A})^{\#}$ & $0^{\#}$ & $q_{e}=0 ; L c=0^{\#}$ & 9 & 40 & $q_{e}=0 ; L_{c}=8$ & 17 & 80 & $q_{e}=0 ; L_{c}=16$ & \multirow{8}{*}{$\begin{array}{l}\Omega_{1}=1000 \mathrm{r} \\
v=45^{\circ} \\
\psi=35^{\circ} \\
q_{0}=3 \mathrm{~mm}\end{array}$} \\
\hline 2 & 5 & $q_{e}=0 ; L c=1$ & 10 & 45 & $q_{e}=0 ; L_{c}=9$ & 18 & 85 & $q_{e}=0 ; L_{c}=17$ & \\
\hline 3 & 10 & $q_{e}=0 ; L_{c}=2$ & $11(\mathrm{C})^{\#}$ & $50^{\#}$ & $q_{e}=0 ; L_{c}=10^{\#}$ & 19 & 90 & $q_{e}=0 ; L_{c}=18$ & \\
\hline 4 & 15 & $q_{e}=0 ; L_{c}=3$ & 12 & 55 & $q_{e}=0 ; L c=11$ & 20 & 95 & $q_{e}=0 ; L_{c}=19$ & \\
\hline 5 & 20 & $q_{e}=0 ; L_{c}=4$ & 13 & 60 & $q_{e}=0 ; L_{c}=12$ & $21(\mathrm{D})^{\#}$ & $100^{\#}$ & $q_{e}=0 ; L_{c}=20^{\#}$ & \\
\hline $6(\mathrm{~B})^{\#}$ & $25^{\#}$ & $q_{e}=0 ; L_{c}=5^{\#}$ & 14 & 65 & $q_{e}=0 ; L_{c}=13$ & $22(\mathrm{E})^{\#}$ & $120^{\#}$ & $q_{e}=3 ; L_{c}=20^{\#}$ & \\
\hline 7 & 30 & $q_{e}=0 ; L_{c}=6$ & 15 & 70 & $q_{e}=0 ; L_{c}=14$ & & & & \\
\hline 8 & 35 & $q_{e}=0 ; L_{c}=7$ & 16 & 75 & $q_{e}=0 ; L_{c}=15$ & & & & \\
\hline
\end{tabular}

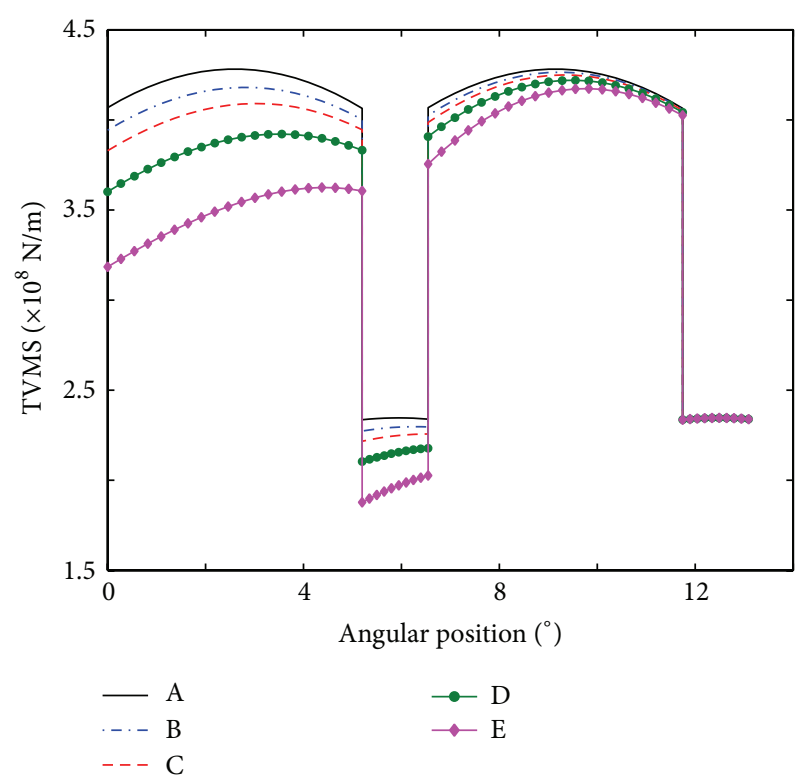

FIGURE 16: TVMS under different crack widths by IM.

tooth width, even if a 3D model is adopted, some difficulties will also occur. So in this section, the comparison of the mesh stiffness between the improved model and the FE model under different crack widths is not carried out. The comparisons of the mean stiffness $k_{m}$ about the five cases are shown in Table 6. It can be seen from Figure 16 and Table 6 that the stiffness decreases with the growth of crack width.

Vibration acceleration responses and the corresponding amplitude spectra are shown in Figure 17. The amplitudes of the impulsive vibration and the magnitudes of sidebands increase with the growth of crack width. For statistical features (see Figure 18), RMS and Kurtosis of original signal increase slightly when the crack width is smaller. When the crack width becomes higher than $80 \%$, Kurtosis exhibits an obvious increasing trend. Reversely, RMS increases slightly. For residual signals, unlike the results obtained from the original signals, RMS shows obvious increasing pattern. In addition, there is a prompt increase for the two indicators when the crack propagates along the whole tooth width and continues to propagate along the crack depth.
TABLE 6: Comparisons of mean TVMS under different crack widths.

\begin{tabular}{lcc}
\hline Case $(\mathrm{IM})$ & $k_{m}\left(\times 10^{8} \mathrm{~N} / \mathrm{m}\right)$ & Reduction percentage \\
\hline A & 3.582 & 0 \\
B & 3.534 & $-1.34 \%$ \\
C & 3.490 & $-2.57 \%$ \\
D & 3.401 & $-5.05 \%$ \\
E & 3.231 & $-9.80 \%$ \\
\hline
\end{tabular}

4.3. Effects of Crack Initial Position. In this section, 12 crack initial position cases are considered which are shown in Table 7. Four cases marked as A (stands for healthy gear), B, C, and D (see Table 7) are selected to study the influences of different crack initial positions on TVMS and vibration responses. The mesh stiffness curves obtained by IM and FEM under the above four cases are displayed in Figure 19. The comparisons of the mean stiffness $k_{m}$ about the four cases are shown in Table 8 . It can be seen from Figure 19 and Table 8 that the stiffness ascends with the increase of the crack initial position angle $\psi$ and the FEM shows the same changing trends as IM.

Vibration acceleration responses and the corresponding amplitude spectra under the four cases are shown in Figure 20. With the growth of initial position angle $\psi$, the amplitudes of the impulsive vibration signals decrease. Similarly, in the acceleration amplitude spectra, the magnitudes of sidebands also decrease with the growth of initial position angle $\psi$.

The variation of statistical indicators acquired from original signals and residual signals with the increase of initial position angle $\psi$ is shown in Figure 21. For residual signals, the relative change ratio of $\psi=65^{\circ} \mathrm{crack}$ is defined as $100 \%$. As seen from the figures, for original signals, Kurtosis exhibits an obvious decreasing trend, while RMS decreases slightly. For residual signals, just the opposite, RMS shows obvious decreasing pattern with the growth of initial position angle $\psi$. In addition, compared with original signals RMS acquired from residual signals changes more obviously.

4.4. Effects of Crack Propagation Direction. In this section, 19 crack propagation direction cases are considered as shown in Table 9. Seven cases marked as A (stands for healthy gear), 


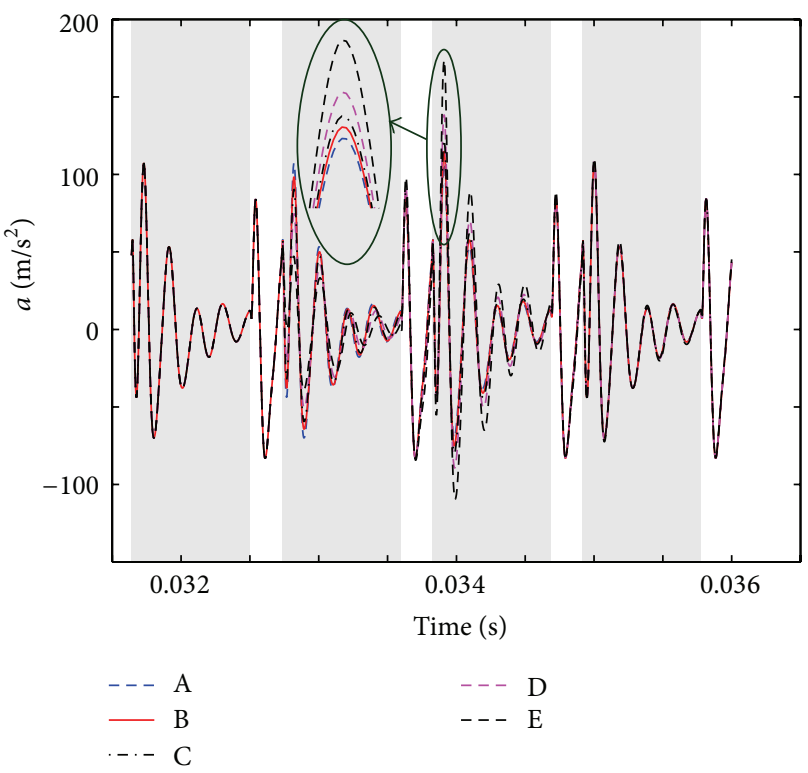

(a)

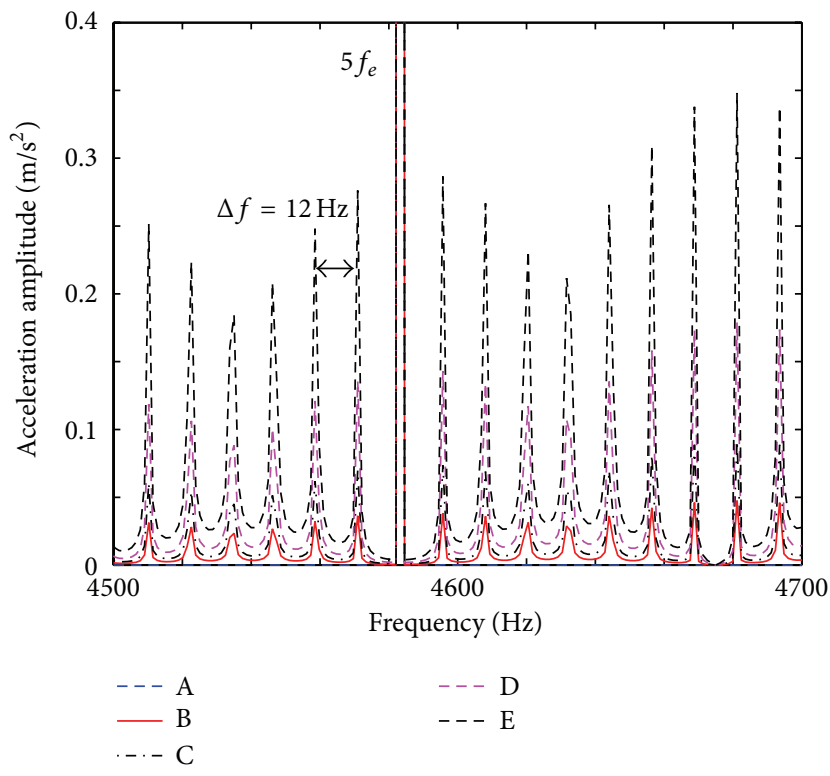

(b)

FIGURE 17: Acceleration responses under different crack widths: (a) time domain waveform and (b) amplitude spectra.

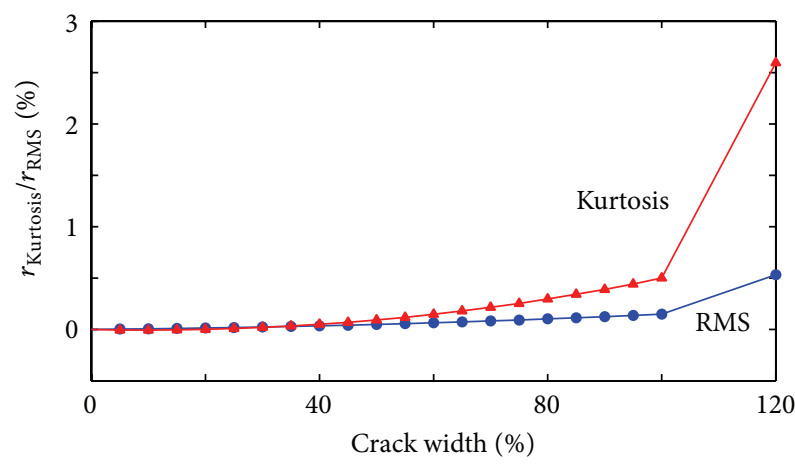

(a)

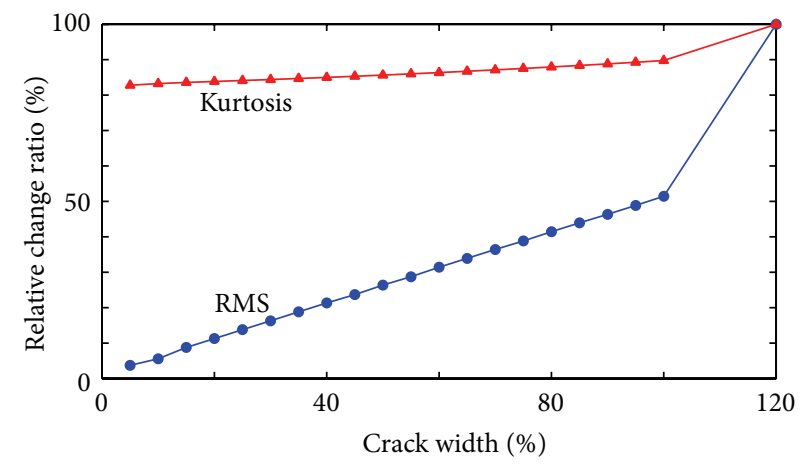

(b)

FIGURE 18: Acceleration statistical indicators under different crack widths: (a) original signal and (b) residual signal (120\% represents the case $L_{c}=L=20 \mathrm{~mm}$ and $\left.q_{e}=q_{0}=3 \mathrm{~mm}\right)$.

TABLE 7: Crack case data under different crack initial positions.

\begin{tabular}{lcccccc}
\hline Crack case & Crack position $\psi\left({ }^{\circ}\right)$ & Crack case & Crack position $\psi\left(^{\circ}\right)$ & Crack case & Crack position $\psi\left(\left(^{\circ}\right)\right.$ & Condition \\
\hline 1 & 15 & 5 & 35 & 9 & 55 & $\Omega_{1}=1000 \mathrm{rev} / \mathrm{min}$ \\
2 & 20 & 6 & 40 & 10 & 60 & $v=45^{\circ}$ \\
$3(\mathrm{~B})^{\#}$ & $25^{\#}$ & $7(\mathrm{C})^{\#}$ & $45^{\#}$ & $11(\mathrm{D})^{\#}$ & $65^{\#}$ & $L_{c}=L=20 \mathrm{~mm}$ \\
4 & 30 & 8 & 50 & 12 & $q_{e}=q_{0}=3 \mathrm{~mm}$ \\
\hline
\end{tabular}

TABLE 8: Comparisons of mean TVMS under different crack initial positions.

\begin{tabular}{lccccc}
\hline Case $(\mathrm{IM})$ & $k_{m}\left(\times 10^{8} \mathrm{~N} / \mathrm{m}\right)$ & Reduction percentage & Case $(\mathrm{FEM})$ & $k_{m}\left(\times 10^{8} \mathrm{~N} / \mathrm{m}\right)$ & Reduction percentage \\
\hline $1 \mathrm{~A}$ & 3.582 & 0 & $2 \mathrm{~A}$ & 3.323 & 0 \\
1B & 3.200 & $-10.66 \%$ & $2 \mathrm{~B}$ & 2.964 & $-10.80 \%$ \\
1C & 3.264 & $-8.88 \%$ & $2 \mathrm{C}$ & 2.997 & $-9.81 \%$ \\
1D & 3.335 & $-6.90 \%$ & $2 \mathrm{D}$ & 3.031 & $-8.79 \%$ \\
\hline
\end{tabular}




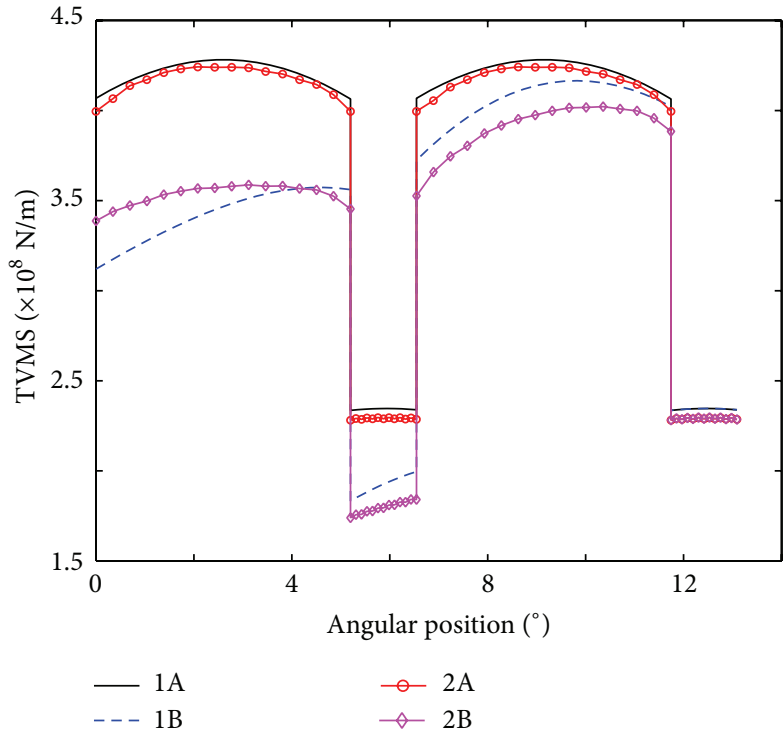

(a)

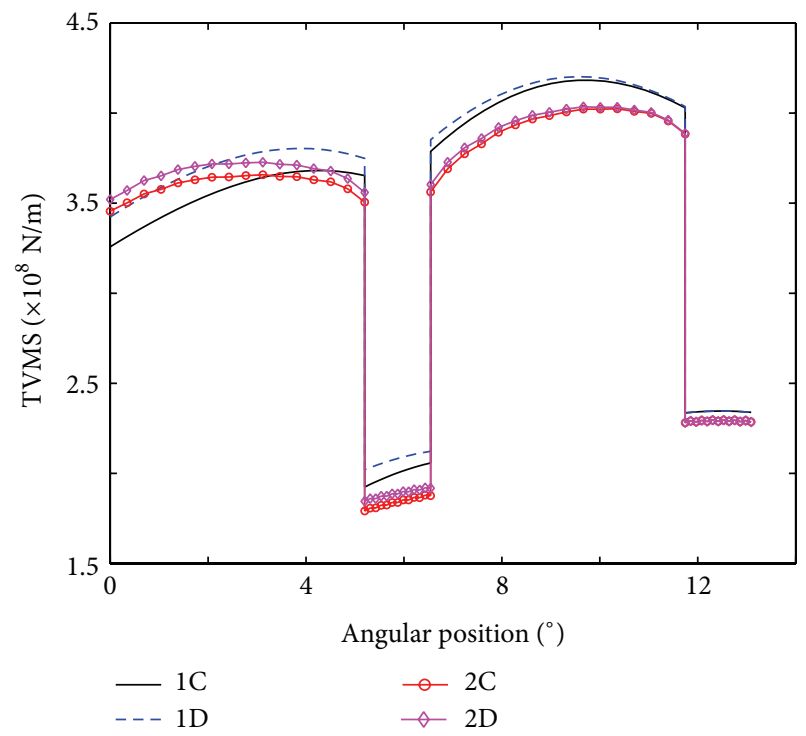

(b)

Figure 19: TVMS under different crack initial positions: (a) crack cases A and B and (b) crack cases C and D.

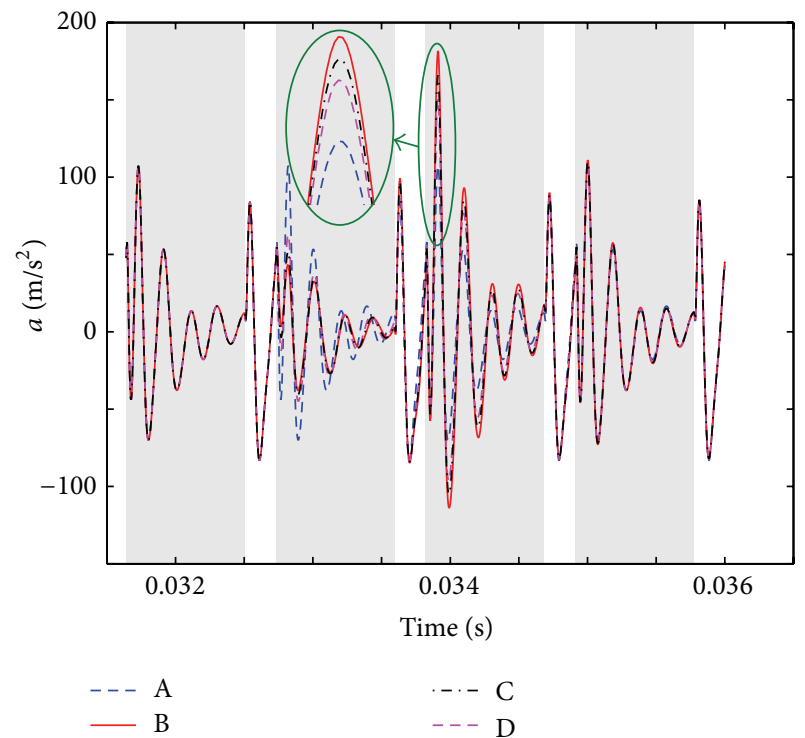

(a)

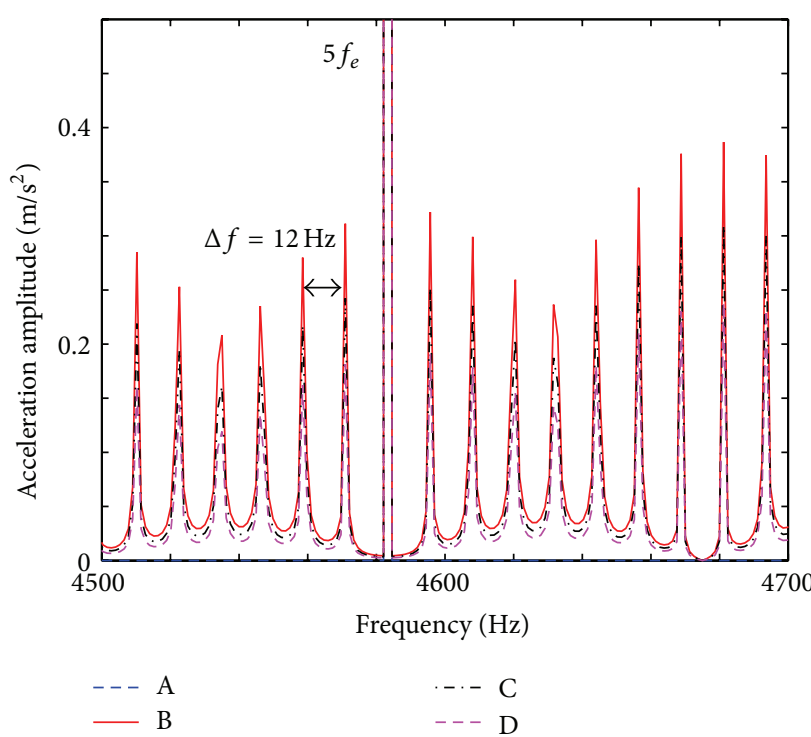

(b)

FIgURE 20: Acceleration responses under different crack initial positions: (a) time domain waveform and (b) amplitude spectra.

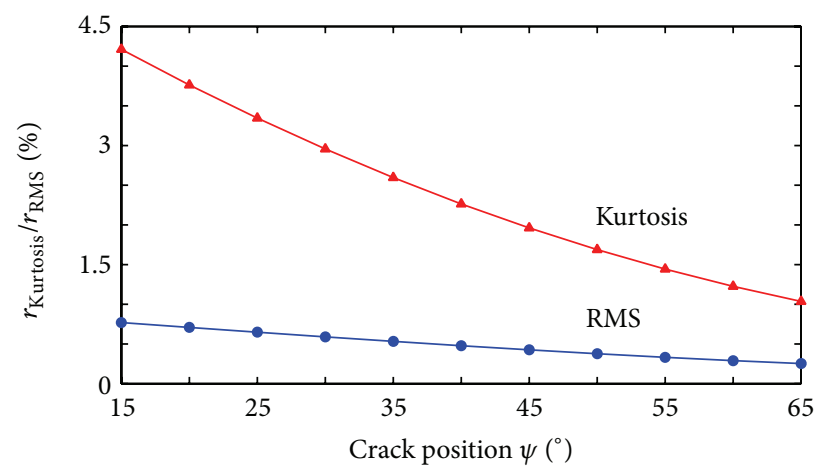

(a)

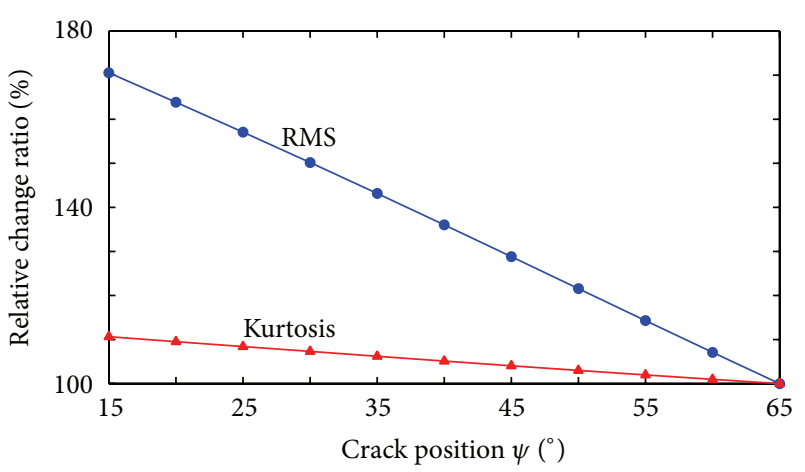

(b)

FIGURE 21: Acceleration statistical indicators under different crack initial positions: (a) original signal and (b) residual signal. 


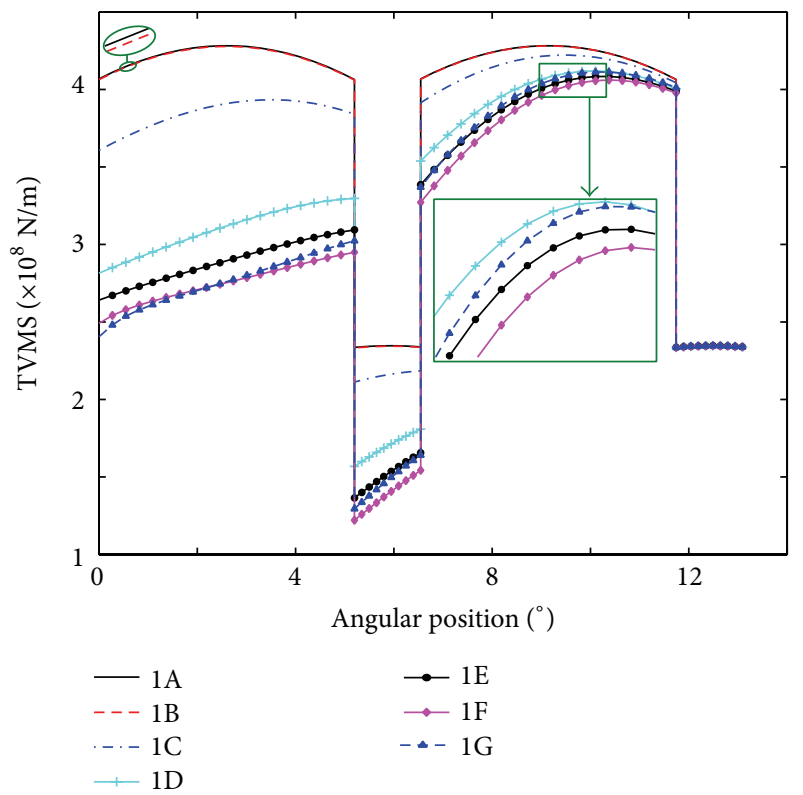

(a)

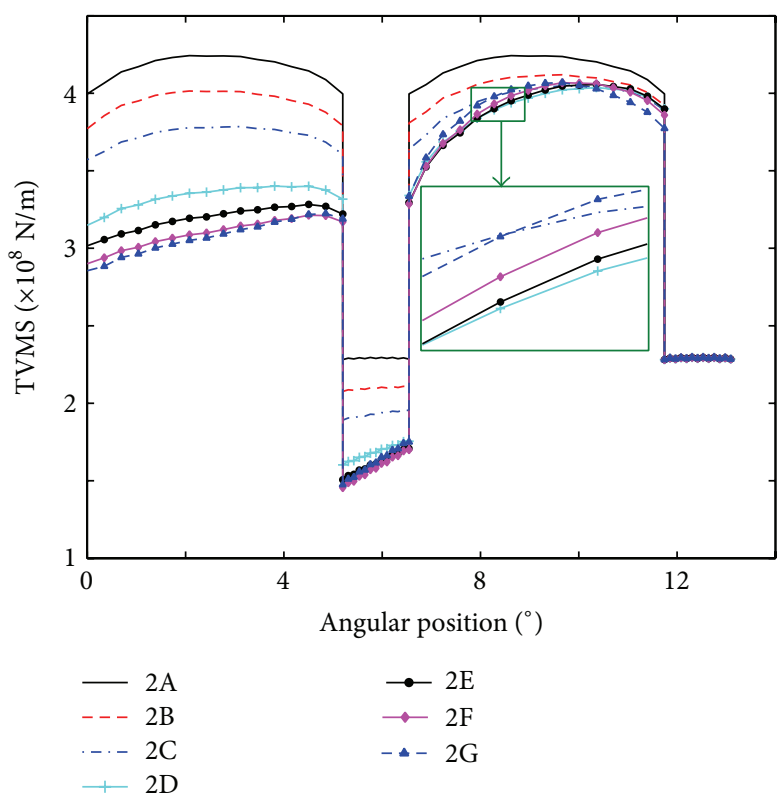

(b)

FIGURE 22: TVMS under different crack propagation directions: (a) IM and (b) FEM.

TABLE 9: Crack case data under different crack propagation directions.

\begin{tabular}{|c|c|c|c|c|c|c|}
\hline Crack case & $\begin{array}{l}\text { Crack propagation } \\
\text { direction } v\left({ }^{\circ}\right)\end{array}$ & Crack case & $\begin{array}{l}\text { Crack propagation } \\
\text { direction } v\left({ }^{\circ}\right)\end{array}$ & Crack case & $\begin{array}{l}\text { Crack propagation } \\
\text { direction } v\left({ }^{\circ}\right)\end{array}$ & Condition \\
\hline $1(\mathrm{~B})^{\#}$ & $0^{\#}$ & 8 & 35 & $15(\mathrm{E})^{\#}$ & $70^{\#}$ & \multirow{7}{*}{$\begin{array}{l}\Omega_{1}=1000 \mathrm{rev} / \mathrm{min} \\
\psi=35^{\circ} \\
L_{c}=L=20 \mathrm{~mm} \\
q_{e}=q_{0}=3 \mathrm{~mm}\end{array}$} \\
\hline 2 & 5 & 9 & 40 & 16 & 75 & \\
\hline 3 & 10 & 10 & 45 & $17(\mathrm{~F})^{\#}$ & $80^{\#}$ & \\
\hline 4 & 15 & 11 & 50 & 18 & 85 & \\
\hline 5 & 20 & 12 & 55 & $19(\mathrm{G})^{\#}$ & $90^{\#}$ & \\
\hline 6 & 25 & $13(\mathrm{D})^{\#}$ & $60^{\#}$ & & & \\
\hline $7(\mathrm{C})^{\#}$ & $30^{\#}$ & 14 & 65 & & & \\
\hline
\end{tabular}

B, C, D, E, F, and G (see Table 9) are chosen to study the influences of crack propagation direction on TVMS and vibration responses.

Based on IM and FEM, the mesh stiffness curves under the above seven cases are displayed in Figure 22. The comparisons of the mean stiffness $k_{m}$ about the seven cases are shown in Table 10. It can be seen from Figure 22 and Table 10 that the stiffness firstly decreases and then increases with the growth of crack propagation direction angle $v$. This is because the involute and transitional part of the gear loses much rigidity and becomes more and more flexible with the increase of crack propagation direction angle $v$; however, a crack with a pretty large $v$ has little effect on the rigidity of the transitional part. The FEM shows the same changing trends as the IM.

Vibration acceleration responses and the corresponding amplitude spectra are shown in Figure 23. The amplitudes of the impulsive vibration and the magnitudes of sidebands firstly increase and then decrease with the growth of propagation direction angle $v$.

The variation of statistical indicators acquired from original signals and residual signals with the increase of propagation direction angle $v$ is shown in Figure 24. For residual signals, the relative change ratio of $v=90^{\circ} \mathrm{crack}$ is defined as $100 \%$. It is seen from the figures that, for original signals, RMS and Kurtosis change a little when the crack propagation direction angle $v$ is less than $50^{\circ}$, and then Kurtosis exhibits an obvious increasing trend and reaches the maximum when $v$ is close to $80^{\circ}$, and after that Kurtosis decreases regularly; RMS has the same phenomenon but changes less obviously. For residual signals, just the opposite, RMS shows obvious increasing pattern with the growth of propagation direction angle $v$ and reaches the maximum when $v$ is close to $80^{\circ}$. In addition, compared with original signals, RMS acquired from residual signals changes more obviously.

\section{Measured Vibration Response of a Cracked Gear Coupled Rotor System}

The one-stage reduction gearbox with crack defect (see Figure 25) is designed to validate the theoretical results, and the parameters of the rotor and the spur gear pair are listed 

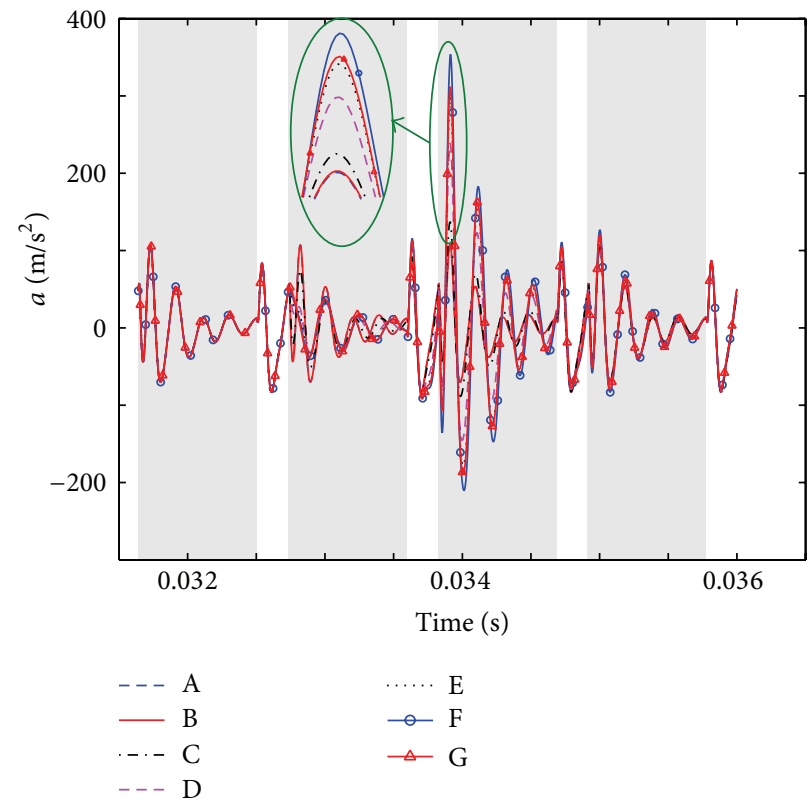

(a)

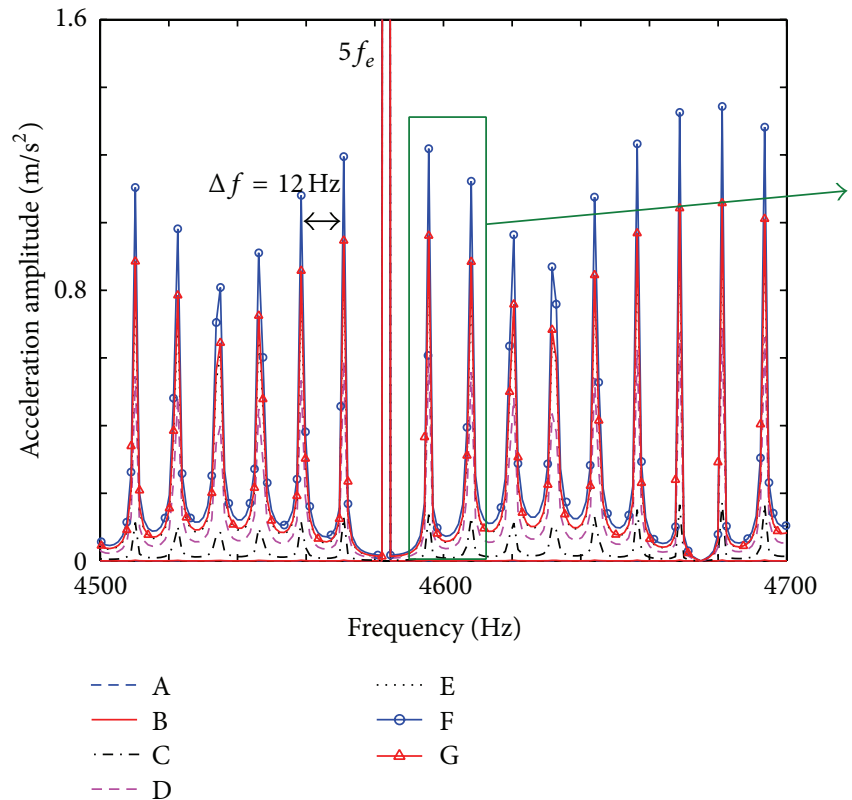

(b)
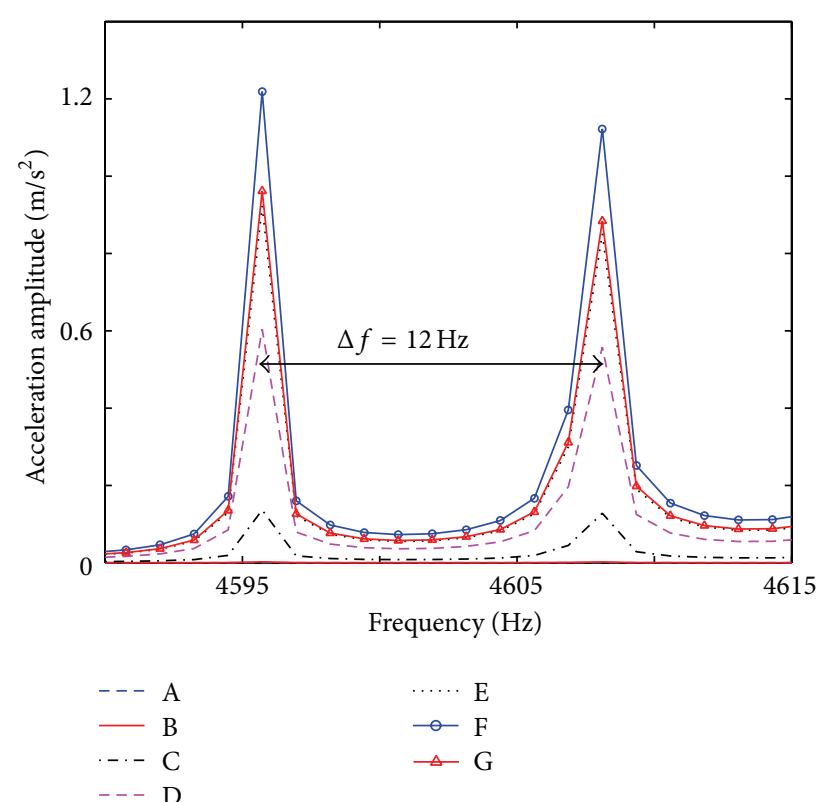

(c)

FIGURE 23: Acceleration responses under different crack propagation directions: (a) time domain waveform, (b) amplitude spectra, and (c) enlarged view of amplitude spectra.

TABLE 10: Comparisons of mean TVMS under different crack propagation directions.

\begin{tabular}{lccccc}
\hline Case $(\mathrm{IM})$ & $k_{m}\left(\times 10^{8} \mathrm{~N} / \mathrm{m}\right)$ & Reduction percentage & Case $(\mathrm{FEM})$ & $k_{m}\left(\times 10^{8} \mathrm{~N} / \mathrm{m}\right)$ & Reduction percentage \\
\hline IA & 3.582 & 0 & $2 \mathrm{~A}$ & 3.323 & 0 \\
1B & 3.580 & $-0.06 \%$ & $2 \mathrm{~B}$ & 3.183 & $-4.21 \%$ \\
1C & 3.406 & $-4.91 \%$ & $2 \mathrm{C}$ & 3.060 & $-7.91 \%$ \\
ID & 3.027 & $-15.49 \%$ & $2 \mathrm{D}$ & 2.879 & $-13.36 \%$ \\
$1 \mathrm{E}$ & 2.905 & $-18.90 \%$ & $2 \mathrm{E}$ & 2.824 & $-15.02 \%$ \\
IF & 2.820 & $-21.27 \%$ & $2 \mathrm{~F}$ & 2.794 & $-15.92 \%$ \\
1G & 2.861 & $-20.13 \%$ & $2 \mathrm{G}$ & 2.797 & $-15.83 \%$ \\
\hline
\end{tabular}




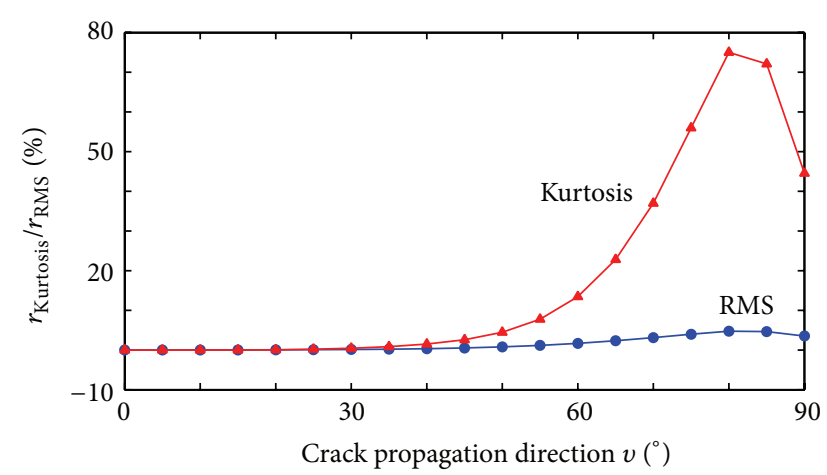

(a)

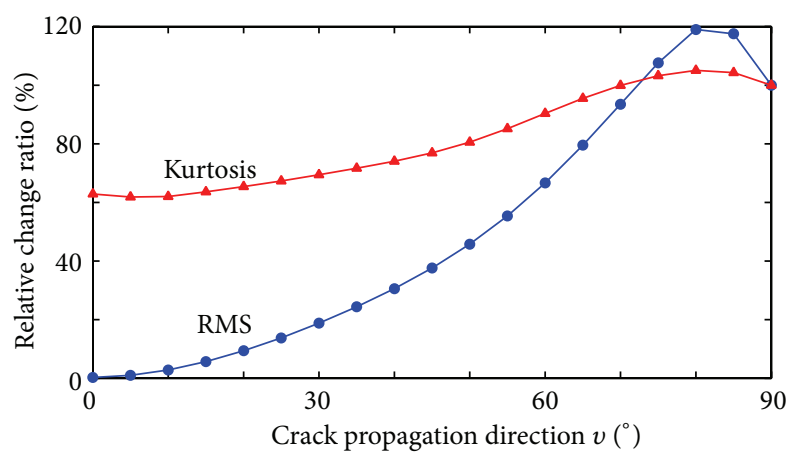

(b)

FIGURE 24: Acceleration statistical indicators under different crack propagation directions: (a) original signal and (b) residual signal.

in Table 2. The crack is manufactured near the root of the driven gear, and the crack depth is $3 \mathrm{~mm}$. Vibration signals under tooth crack condition are measured by accelerometers whose locations are shown in Figure 25. The sample frequency is $10000 \mathrm{~Hz}$ and the rotating speed of driving shaft is $1000 \mathrm{rev} / \mathrm{min}$. So rotating frequencies of the driving and driven gear are about $16.7 \mathrm{~Hz}$ and $12.2 \mathrm{~Hz}$, which are denoted by $f_{1}$ and $f_{2}$, respectively, and meshing frequency $f_{e}$ is equal to $916.7 \mathrm{~Hz}$. Time domain waveform of the vibration acceleration and its frequency spectrum at the right bearing of the driving shaft in vertical direction of healthy gear system and cracked gear system are displayed in Figures 26 and 27, respectively.

Comparation with Figures 26(a) and 27(a) shows the existence of large impulse under crack state, and frequency of impulse $1 / \Delta t=12.2 \mathrm{~Hz}$ is just the rotating frequency of the cracked gear. The impulse displayed in Figure 27(a) shows the same features as that in Figure 10(b). For the healthy geared rotor system and cracked geared rotor system, the amplitude spectra all show the meshing frequency and its harmonics (see Figures 26(b) and 27(b)). Moreover, there also exist interference frequencies and sideband frequencies. For healthy geared rotor system, probably due to the mismachining tolerance, sideband frequencies around the meshing frequency and its harmonics are detected, which are related to the rotating frequency of the driving gear $f_{1}$; for example, $932.8 \mathrm{~Hz} \approx f_{e}+f_{1}, 1815 \mathrm{~Hz} \approx 2 f_{e}-f_{1}$. For cracked geared rotor system, the sideband frequency components around meshing frequency and its harmonics are different from healthy system, which are related to the rotating frequency of the driven gear; for example, $903.5 \mathrm{~Hz} \approx f_{e}-f_{2}, 1844 \mathrm{~Hz} \approx$ $2 f_{e}+f_{2}$.

In addition, owing to the influences of many factors, such as the accuracy of involute cylindrical gears, variations of bearing stiffness, friction, interference of current, and noise on experiment results, frequency components of system are complicated and many interference frequency components appear, which leads to irregular shock in time domain waveform of healthy geared rotor system. But even if there are a lot of uncertain factors, for cracked geared rotor system, the vibration responses of the experimental signal agree with the theoretical results.

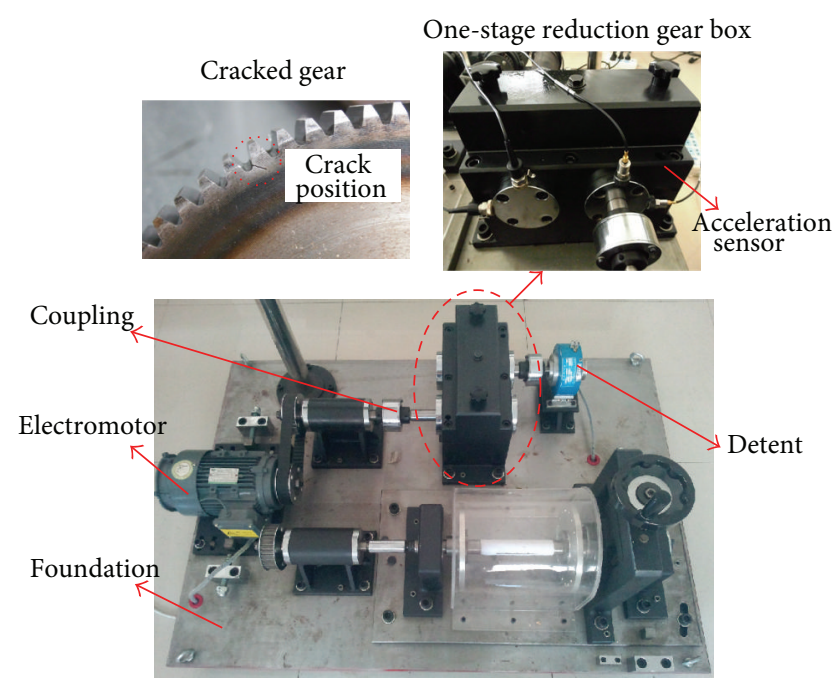

FIGURE 25: Test rig of a cracked gear coupled rotor system.

\section{Conclusions}

Considering the misalignment of gear root circle and base circle, an improved mesh stiffness model for a healthy gear pair is proposed, and it is validated by comparison with the FE results. On the basis of the improved method, a mesh stiffness model for a cracked gear pair is established. Then the mesh stiffness is introduced into a geared rotor system to simulate the vibration response under different crack cases. The effects of tooth crack parameters including crack depth, width, initial position, and crack propagation direction on gear mesh stiffness, vibration responses, and statistical indicators are investigated. In the end, an experiment of the gearbox with a cracked tooth in driven gear has been designed to validate the failure characteristics. Some conclusions can be summarized as follows.

(1) The improved mesh stiffness model in which the gear tooth is modeled as a nonuniform cantilever beam on the root circle is more accurate compared with the traditional mesh stiffness model in which the gear 


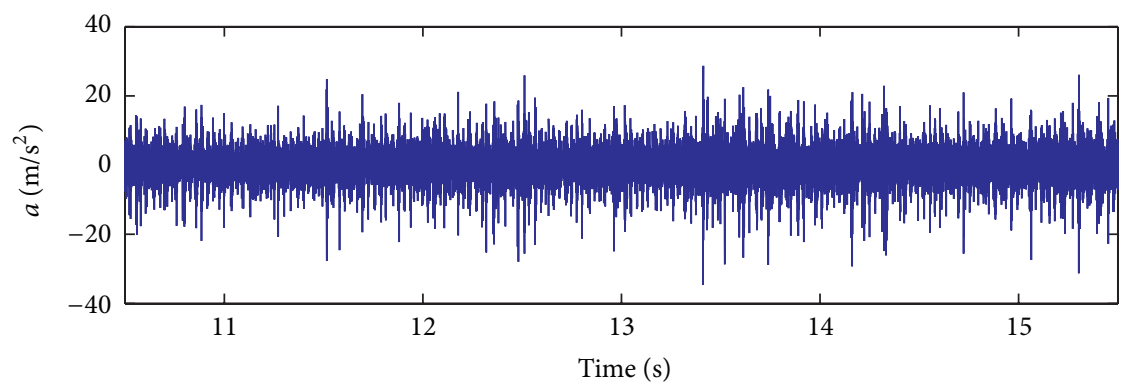

(a)
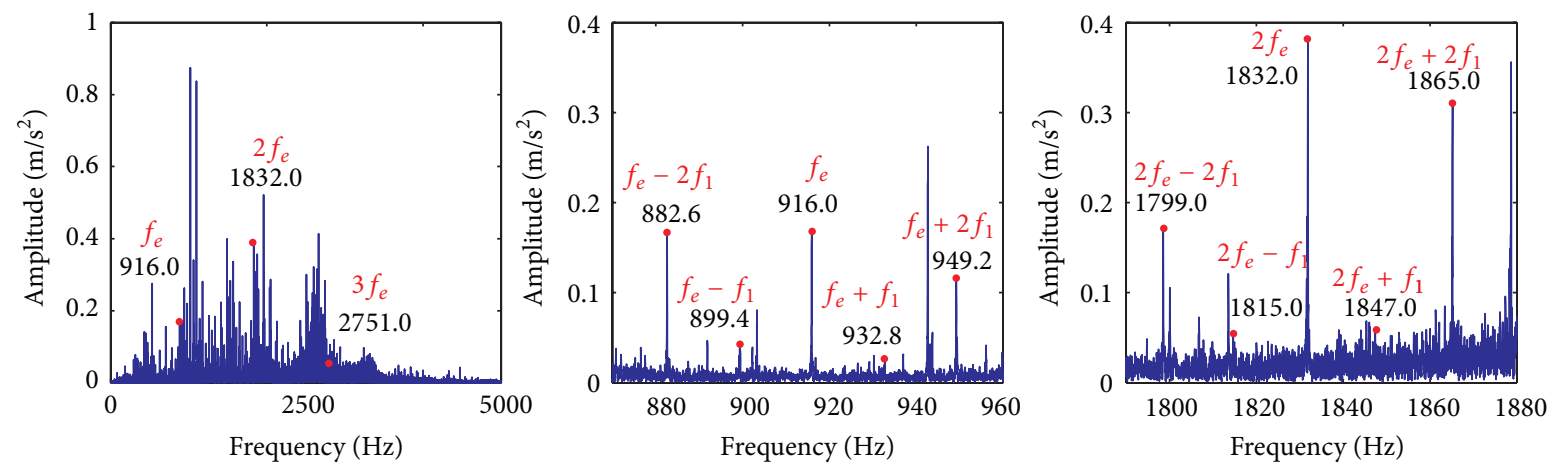

(b)

FIGURE 26: Measured acceleration responses of healthy gear: (a) time domain waveform and (b) amplitude spectra.

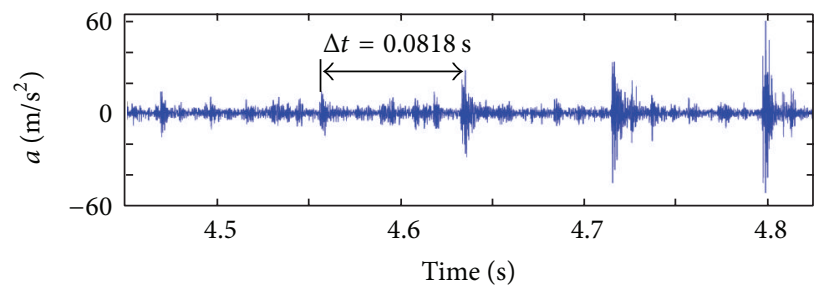

(a)
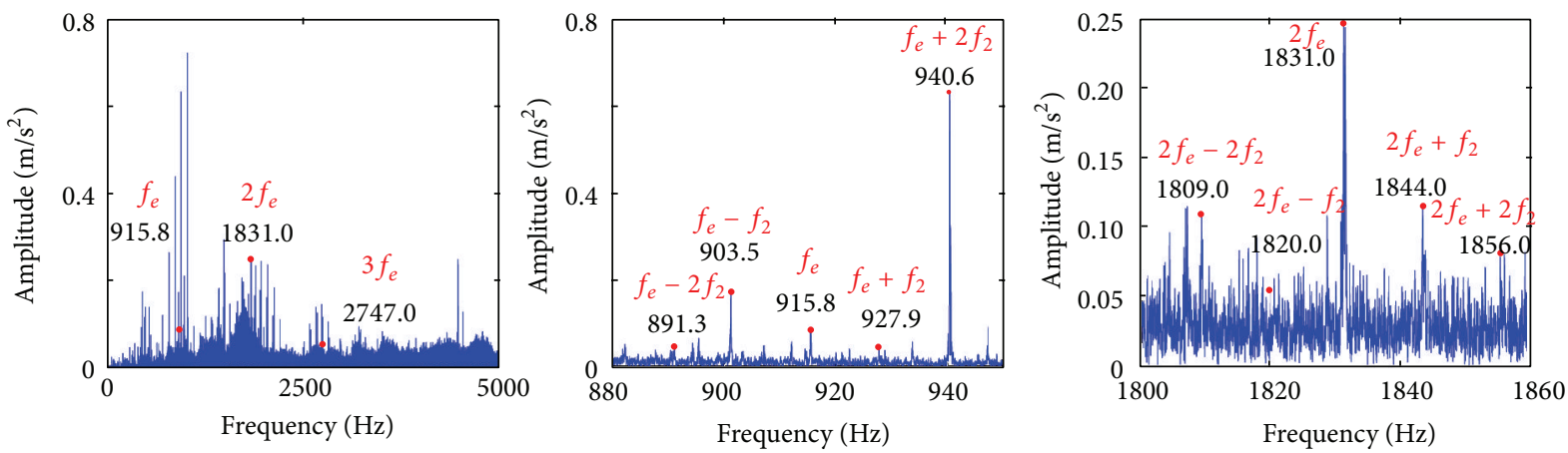

(b)

FIGURE 27: Measured acceleration responses of cracked gear: (a) time domain waveform and (b) amplitude spectra.

tooth is modeled as a cantilever beam on the base circle.

(2) When tooth crack is introduced, distinct reduction of stiffness can be observed and the stiffness decreases with the growth of crack depth and width, increases with the increasing crack initial position angle $\psi$, and firstly decreases and then increases with the increasing crack propagation direction angle $v$.

(3) When tooth root crack is introduced, distinct impulses are found in time domain vibration responses and 
the time interval between every two adjacent impulses is exactly equal to the rotating period of the cracked gear. In frequency domain, the amplitudes of meshing frequency and its harmonics hardly change compared with healthy gear, but the sidebands appear under the tooth crack condition. The interval between every two sideband components is exactly equal to the rotating frequency of the cracked gear. The amplitudes of the impulses and the magnitudes of sidebands increase with the growth of crack depth and width, decrease with the increase of crack initial position angle $\psi$, and firstly increase and then decrease with the growth of crack propagation direction angle $v$. In addition, time and frequency domain vibration features measured by the experiment agree qualitatively with the analytical results.

(4) RMS and Kurtosis indicators acquired from original signals and residual signals are used to analyze the effect of different crack parameters. When crack depth, width, and propagation direction angle are smaller, it is hard to detect the presence of crack due to the little change of these statistical features. Amplitudes of all the statistical indicators ascend gradually with the growth of crack depth and width, decrease with the increase of crack initial position angle $\psi$, and firstly increase and then decrease with the growth of propagation direction angle $v$. In addition, for original signals, Kurtosis changes more obviously, and for residual signals, RMS shows obvious changing pattern. But compared with original signals, RMS acquired from residual signals changes more obviously.

It is worth mentioning that the improved mesh stiffness model proposed in this paper cannot deal with this situation when the tooth crack propagates to the foundation of the gear. In future articles, emphasis will be given to the effect of tooth crack on the rigidity of the foundation. In addition, a 3D model considering the crack propagation along tooth width is another research focus.

\section{Appendix}

$x_{\beta}, y_{\beta}, x_{1}, y_{1}, x_{2}, y_{2}, I_{y 1}, I_{y 2}, A_{y 1}$, and $A_{y 2}$ can be expressed as the function of angular $\gamma, \beta$, or $\tau$, which can be expressed as

$$
\begin{gathered}
x_{\beta}=r_{b}\left[\left(\beta+\theta_{b}\right) \cos \beta-\sin \beta\right], \\
y_{\beta}=r_{b}\left[\left(\beta+\theta_{b}\right) \sin \beta+\cos \beta\right], \\
x_{1}=r \times \sin (\Phi)-\left(\frac{a_{1}}{\sin \gamma+r_{\rho}}\right) \times \cos (\gamma-\Phi), \\
y_{1}=r \times \cos (\Phi)-\left(\frac{a_{1}}{\sin \gamma+r_{\rho}}\right) \times \sin (\gamma-\Phi) .
\end{gathered}
$$

$$
\begin{gathered}
x_{2}=r_{b}\left[\left(\tau+\theta_{b}\right) \cos \tau-\sin \tau\right], \\
y_{2}=r_{b}\left[\left(\tau+\theta_{b}\right) \sin \tau+\cos \tau\right], \\
A_{y 1}=2 x_{1} L, \\
A_{y 2}=2 x_{2} L, \\
I_{y 1}=\frac{2}{3} x_{1}^{3} L, \\
I_{y 2}=\frac{2}{3} x_{2}^{3} L .
\end{gathered}
$$

So $\mathrm{d} y_{1} / \mathrm{d} \gamma$ and $\mathrm{d} y_{2} / \mathrm{d} \tau$ can be calculated as follows:

$$
\begin{aligned}
& \frac{\mathrm{d} y_{1}}{\mathrm{~d} \gamma}= \frac{a_{1} \sin \left(\left(a_{1} / \tan \gamma+b_{1}\right) / r\right)\left(1+\tan ^{2} \gamma\right)}{\tan ^{2} \gamma} \\
&+\frac{a_{1} \cos \gamma}{\sin ^{2} \gamma} \sin \left(\gamma-\frac{a_{1} / \tan \gamma+b_{1}}{r}\right)-\left(\frac{a_{1}}{\sin \gamma}+r_{\rho}\right) \\
& \times \cos \left(\gamma-\frac{a_{1} / \tan \gamma+b_{1}}{r}\right)\left(1+\frac{a_{1}\left(1+\tan ^{2} \gamma\right)}{r \tan ^{2} \gamma}\right), \\
& \frac{\mathrm{d} y_{2}}{\mathrm{~d} \tau}=r_{b}\left(\tau+\theta_{b}\right) \cos \tau,
\end{aligned}
$$

where $\theta_{b}$ is the half tooth angle on the base circle of the gear, $\theta_{b}=\pi / 2 N+\operatorname{inv} \alpha$.

\section{Conflict of Interests}

The authors declare that there is no conflict of interests regarding the publication of this paper.

\section{Acknowledgments}

The authors are grateful to the Program for New Century Excellent Talents in University (Grant no. NCET-11-0078) and the Fundamental Research Funds for the Central Universities (Grant no. N130403006) for providing financial support for this work.

\section{References}

[1] D. C. H. Yang and J. Y. Lin, "Hertzian damping, tooth friction and bending elasticity in gear impact dynamics," Journal of Mechanisms, Transmissions, and Automation in Design, vol. 109, no. 2, pp. 189-196, 1987.

[2] X. H. Tian, Dynamic simulation for system response of gearbox including localized gear faults [M.S. thesis], University of Alberta, Edmonton, Canada, 2004.

[3] S. Wu, Gearbox dynamic simulation and estimation of fault growth [M.S. thesis], University of Alberta, Edmonton, Canada, 2007.

[4] X. Zhou, Y. Shao, Y. Lei, and M. Zuo, “Time-varying meshing stiffness calculation and vibration analysis for a 16DOF dynamic 
model with linear crack growth in a pinion," Journal of Vibration and Acoustics, Transactions of the ASME, vol. 134, no. 1, Article ID 011011, 2012.

[5] P. Sainsot, P. Velex, and O. Duverger, "Contribution of gear body to tooth deflections-a new bidimensional analytical formula," Journal of Mechanical Design, Transactions of the ASME, vol. 126, no. 4, pp. 748-752, 2004.

[6] F. Chaari, T. Fakhfakh, and M. Haddar, "Analytical modelling of spur gear tooth crack and influence on gearmesh stiffness," European Journal of Mechanics A/Solids, vol. 28, no. 3, pp. 461468, 2009.

[7] Z. Wan, Y. Zi, H. Cao, Z. He, and S. Wang, "Time-varying mesh stiffness algorithm correction and tooth crack dynamic modeling," Journal of Mechanical Engineering, vol. 49, no. 11, pp. 153160, 2013.

[8] Z. Chen and Y. Shao, "Mesh stiffness calculation of a spur gear pair with tooth profile modification and tooth root crack," Mechanism and Machine Theory, vol. 62, pp. 63-74, 2013.

[9] A. Fernandez Del Rincon, F. Viadero, M. Iglesias, P. García, A. De-Juan, and R. Sancibrian, "A model for the study of meshing stiffness in spur gear transmissions," Mechanism and Machine Theory, vol. 61, pp. 30-58, 2013.

[10] S. Jia and I. Howard, "Comparison of localised spalling and crack damage from dynamic modelling of spur gear vibrations," Mechanical Systems and Signal Processing, vol. 20, no. 2, pp. 332349, 2006.

[11] J. Wang and I. Howard, "Finite element analysis of High Contact Ratio spur gears in mesh," Journal of Tribology, vol. 127, no. 3, pp. 469-483, 2005.

[12] J. F. Li, M. T. Xu, and S. Y. Wang, "Finite element analysis of instantaneous mesh stiffness of cylindrical gears (with and without flexible gear body)," Communications in Numerical Methods in Engineering, vol. 15, no. 8, pp. 579-587, 1999.

[13] J. D. Wang, Numerical and experimental analysis of spur gears in mesh [Ph.D. thesis], Curtin University of Technology, Bentley, Australia, 2003.

[14] J. Wang and I. Howard, "The torsional stiffness of involute spur gears," Proceedings of the Institution of Mechanical Engineers C: Journal of Mechanical Engineering Science, vol. 218, no. 1, pp. 131142, 2004.

[15] D. G. Lewicki and R. Ballarini, "Effect of rim thickness on gear crack propagation path," Journal of Mechanical Design, Transactions of the ASME, vol. 119, no. 1, pp. 88-95, 1997.

[16] Y. Pandya and A. Parey, "Failure path based modified gear mesh stiffness for spur gear pair with tooth root crack," Engineering Failure Analysis, vol. 27, pp. 286-296, 2013.

[17] Y. Pandya and A. Parey, "Simulation of crack propagation in spur gear tooth for different gear parameter and its influence on mesh stiffness," Engineering Failure Analysis, vol. 30, pp. 124-137, 2013.

[18] S. Zouari, M. Maatar, T. Fakhfakh, and M. Haddar, "Following spur gear crack propagation in the tooth foot by finite element method," Journal of Failure Analysis and Prevention, vol. 10, no. 6, pp. 531-539, 2010.

[19] S. Wu, M. J. Zuo, and A. Parey, "Simulation of spur gear dynamics and estimation of fault growth," Journal of Sound and Vibration, vol. 317, no. 3-5, pp. 608-624, 2008.

[20] Z. Chen and Y. Shao, "Dynamic simulation of spur gear with tooth root crack propagating along tooth width and crack depth," Engineering Failure Analysis, vol. 18, no. 8, pp. 21492164, 2011.
[21] O. D. Mohammed, M. Rantatalo, and J. Aidanpaa, "Improving mesh stiffness calculation of cracked gears for the purpose of vibration-based fault analysis," Engineering Failure Analysis, vol. 34, pp. 235-251, 2013.

[22] R. Ma and Y. Chen, "Research on the dynamic mechanism of the gear system with local crack and spalling failure," Engineering Failure Analysis, vol. 26, pp. 12-20, 2012.

[23] A. Kahraman, H. N. Ozguven, D. R. Houser, and J. J. Zakrajsek, "Dynamic analysis of geared rotors by finite elements," Journal of Mechanical Design, Transactions of the ASME, vol. 114, no. 3, pp. 507-514, 1992.

[24] J. S. Rao, T. N. Shiau, and J. R. Chang, "Theoretical analysis of lateral response due to torsional excitation of geared rotors," Mechanism and Machine Theory, vol. 33, no. 6, pp. 761-783, 1998.

[25] M. Kubur, A. Kahraman, D. M. Zini, and K. Kienzle, "Dynamic analysis of a multi-shaft helical gear transmission by finite elements: model and experiment," Journal of Vibration and Acoustics, Transactions of the ASME, vol.126, no. 3, pp. 398-406, 2004.

[26] A. S. Lee, J. W. Ha, and D.-H. Choi, "Coupled lateral and torsional vibration characteristics of a speed increasing geared rotor-bearing system," Journal of Sound and Vibration, vol. 263, no. 4, pp. 725-742, 2003.

[27] A. S. Lee and J. W. Ha, "Prediction of maximum unbalance responses of a gear-coupled two-shaft rotor-bearing system," Journal of Sound and Vibration, vol. 283, no. 3-5, pp. 507-523, 2005.

[28] Q. Han, J. Zhao, and F. Chu, "Dynamic analysis of a geared rotor system considering a slant crack on the shaft," Journal of Sound and Vibration, vol. 331, no. 26, pp. 5803-5823, 2012.

[29] Y. Cui, Z. Liu, Y. Wang, and J. Ye, "Nonlinear dynamic of a geared rotor system with nonlinear oil film force and nonlinear mesh force," Journal of Vibration and Acoustics, Transactions of the ASME, vol. 134, no. 4, Article ID 041001, 2012.

[30] P. Velex and M. Ajmi, "On the modelling of excitations in geared systems by transmission errors," Journal of Sound and Vibration, vol. 290, no. 3-5, pp. 882-909, 2006.

[31] H. Ma, J. Yang, R. Z. Song et al., "Effects of tip relief on vibration responses of a geared rotor system," Proceedings of the Institution of Mechanical Engineers C: Journal of Mechanical Engineering Science, vol. 28, pp. 1132-1154, 2014.

[32] F. K. Omar, K. A. F. Moustafa, and S. Emam, "Mathematical modeling of gearbox including defects with experimental verification," Journal of Vibration and Control, vol. 18, no. 9, pp. 1310$1321,2012$.

[33] S. Jia, I. Howard, and J. Wang, "The dynamic modeling of multiple pairs of spur gears in mesh, including friction and geometrical errors," International Journal of Rotating Machinery, vol. 9, pp. 437-442, 2003.

[34] Z. Guo and Y. D. Zhang, "Parameterization precise modeling of involutes spur gear based on APDL," Machinery Manufacturing and Research, vol. 39, pp. 33-36, 2010. 


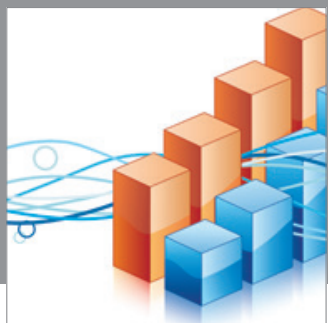

Advances in

Operations Research

mansans

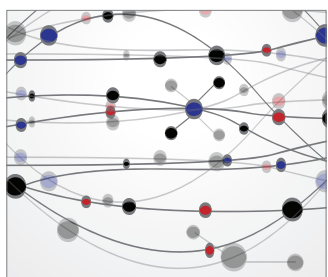

The Scientific World Journal
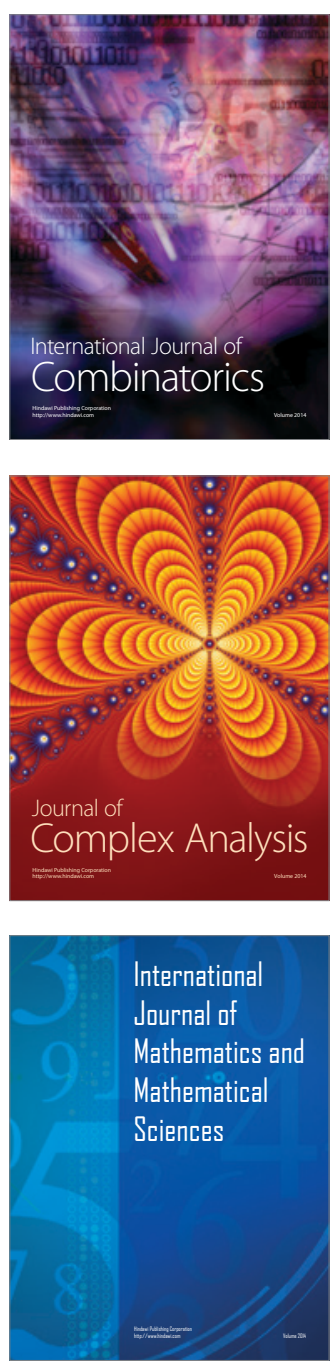
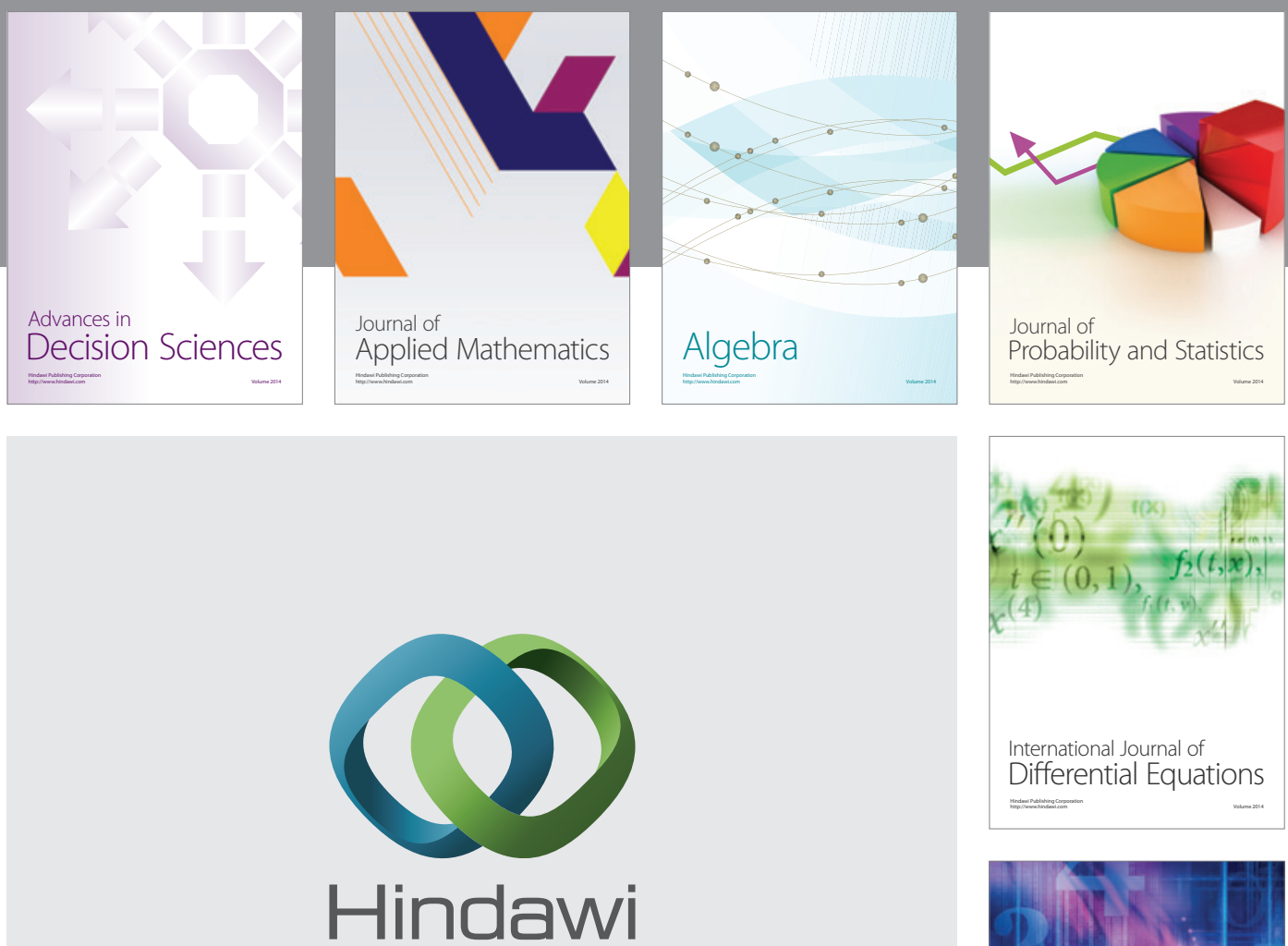

Submit your manuscripts at http://www.hindawi.com
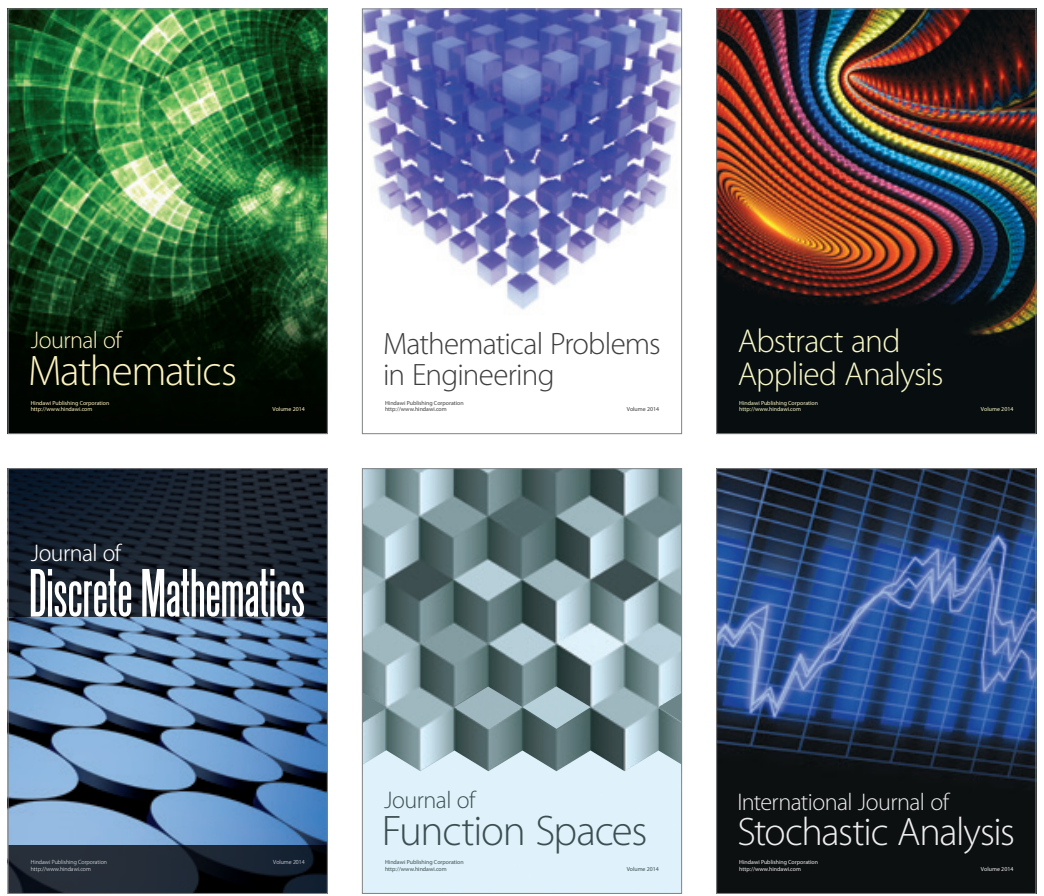

Journal of

Function Spaces

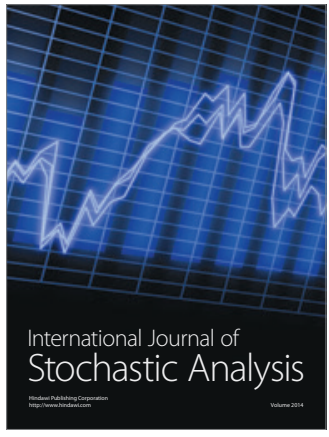

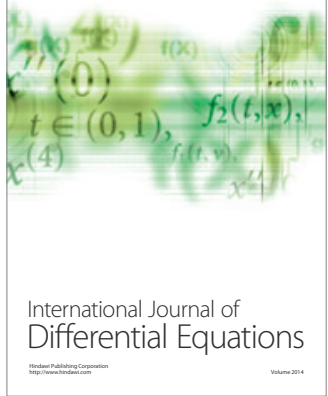
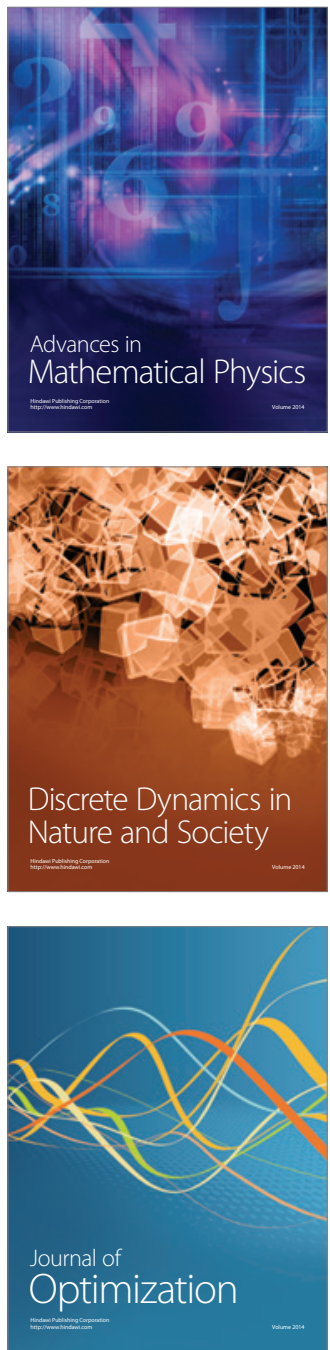